\title{
" واقع تسويق المنشآت الرياضية بمحافظة أسوان "
}

\section{أ. د. / عادل عبدالمنهم هكي

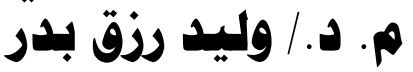

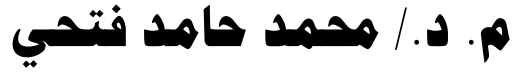

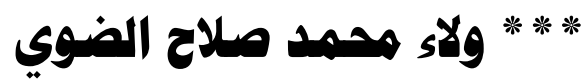

\section{المقدمة ومشكلة البحث:}

تعد الإدارة عملية إنسانية مستمرة تعمل على تحقيق أهداف جيدة وعلى استخدام الجهد البشرى في الاستعانة بالإمكانيات البشرية والمادية المتاحة، وذلك الكانك

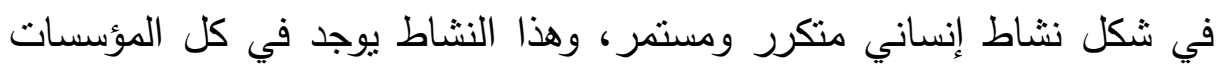
وعلى كافة المستويات سواء كانت هذه المؤسسات حكومية أو أهلية .(1) (1)

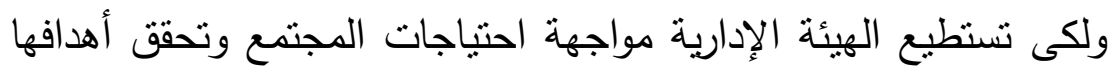
بنجاح ينطلب على القائمين بها وقادتها أن يكون لايهم روئية واحدة مشتركة في الإني

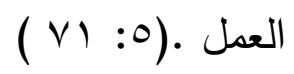

ولقد بدأت الإدارات في المؤسسات المعاصرة تلجأ إلى تطوير الأفكار

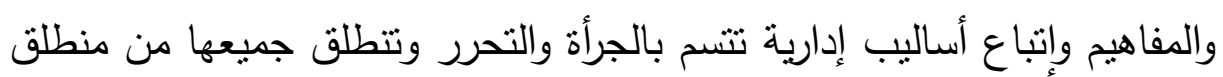

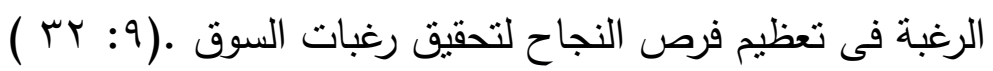

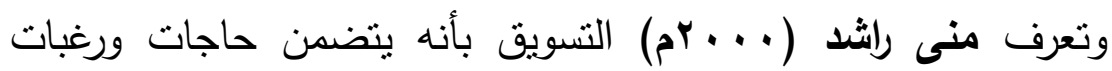

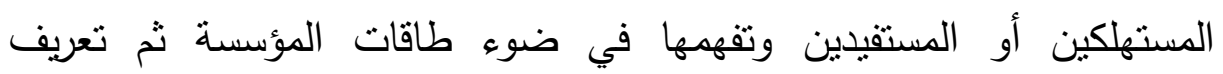
المختص بنلك الرغبات والحاجات حتى يمكن تتكيل المنتج والخدمة وفقا لها ثم

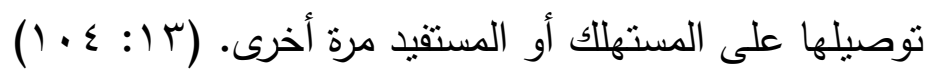




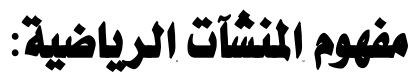

وعرفها سمير عبد الحميد (Y . . . بأنها مؤسسات تربوية تهدف إلى إعداد

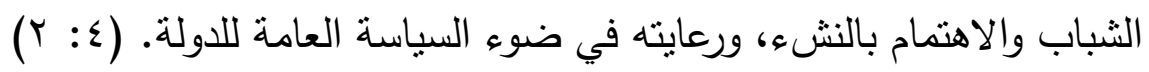
مشكلة البحث وأهميته: - مابه ومن خلال اطلاع الباحثة علي بعض المراجع والدوريات واللوائح المنظمة

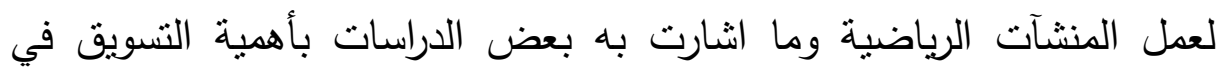

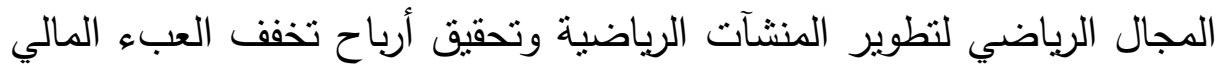
عن الدولة وتواكب سعيها وتأكيدها علي أهمية تطوير الرياضة المصرية ، وعمل تغيير جذري في صناعة الرياضة وتحويلها من نشاط مستهلك الي نشاط

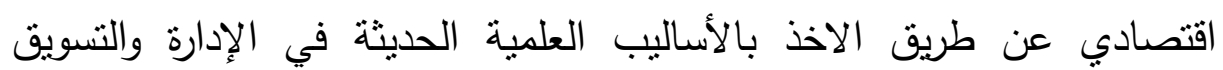

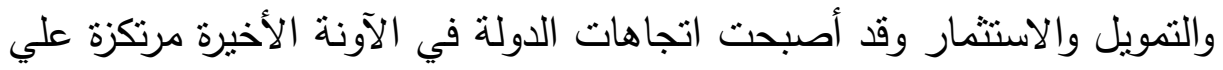
توسيع قاعدة التسويق الرياضي من خلال المنشآت الرياضية وزيادة العائد المادي والاقتصادي لها عن طريق انشاء وتطوير وتسويق المنشآت الرياضية بمحافظات جمهورية مصر العربية وهي (الأندية ـالصالات -حمامات السباحة -الملاعب المفتوحة - فنادق الرياضيين - صالات اللياقة البدنية - وحدات الطب الرياضي ) وغيرها من المنشآت الرياضية .

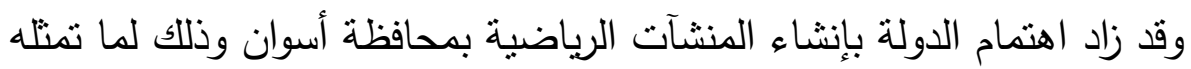
من مناطق سياحية تكون مصدر جذب وانتباه للكثير من الجنسيات المختلفة في العالم ،حيث ان لديها من الحضارة والتاريخ ما يؤهلها لذلك ، حيث بها الكثير من اثار العالم وتتوفر لايها عوامل الجذب السياحي مما يشجع علي جذب رؤوس الأموال والاستثمار في المناطق السياحية والرياضية بمحافظة أسوان ـ ومن خلال الدراسة الاستطلاعية التي أجرتها الباحثة علي بعض مديري المنشآت الرياضية بمحافظة أسوان تبين انه يوجد قصور في اللوائح والقوانين

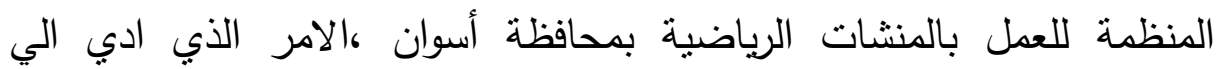


مواجهة المنشآت الرياضية لكثير من المعوقات التي تحول دون تسويقها بالطريقة

$$
\text { أهمية البحث : }
$$

ترجع الأهمية العلمية لهذا البحث في الاعتبارات التالية:

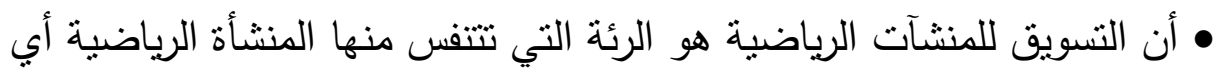
ما كان مصادر دخلها فأن التسويق هو عماد التمويل. • تقوم الإدارة العليا بعطية التخطيط للتسويق واتخاذ القرارات بناءاً عن ما تقدمه هونه

$$
\begin{aligned}
& \text { الإدارة المباشرة من معلومات إليها. } \\
& \text { هدف البحث: } \\
& \text { يهدف البحث إلى: }
\end{aligned}
$$

• التعرف على الواقع الحالي لتسويق المنشآت الرياضية بمحافظة أسوان.

$$
\text { تساويلات البحث: }
$$

•ما هو الواقع الحالي لتسويق المنشآت الرياضية بمحافظة أسوان؟

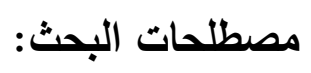

$$
\text { التسويق الرياضي: }
$$

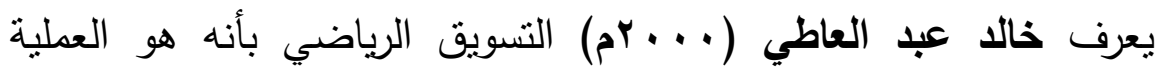
القائمة المتبادلة المنافع بين المنتج (البطولات الرياضية) وبين المستهلك (المشاهدين) لتحقيق هدفه الأساسي لإشباع وتوفير احتياجات المجتمع المعنوي

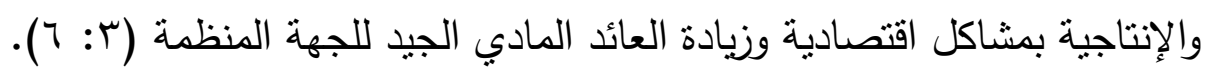

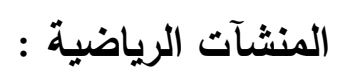

عرفت الهيئة العامة للشباب والرياضية (9 ه . . rم) المنشآت الرباضية بأنها: المرافق الرياضية والأندية ومراكز الثباب والصالات المفتوحة والمغطاة التي تم إنشائها لتمكين أفراد المجتمع في مراحل سنية مختلفة من ممارسة هواياتهم ونشاطاتهم الرياضية. (1: ( ) 


\section{الدراسات المرجعية:

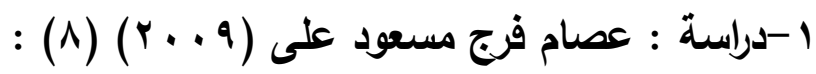

موضوع الدراسة :"تقويم الموارد المادية والبشرية بمراكز الثباب بمحافظة المنوفية" أهداف الدراسة : (المنه

1 - التعرف على الموارد المادية والبشرية بمراكز الثباب بمحافظة المنوفية . r- إقتراح الحلول المناسبة للمشكلات المرتبطة بالموارد المادية والبشرية .

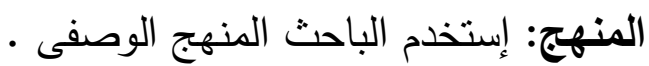
العينة : بلغ إجمالى أفراد العينة (·VV) فرداً بمراكز الثباب بمحافظة المنوفية وهم عضو مجلس إدارة ومدير المركز وأخصائى رياضى أو مشرف رياضى من لهن مراكز شباب المدن والقرى بمحافظة المنوفية أدوات جمع البيانات : تم جمع البيانات عن طريق الإستبيان •

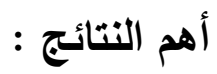
تم التوصل إلى أهم المشكلات المرتبطة بالموارد المادية والبشرية بمراكز الثباب بمحافظة المنوفية ، وأمكن وضع الحلول المناسبة لتلك المشكلات للنهوض بمراكز شباب القرى والمدن بمحافظة المنوفية .

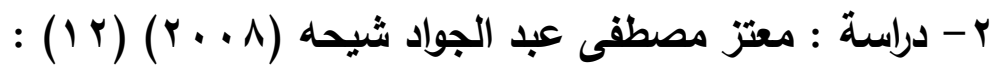
موضوع الدراسة : "مدخل إدارى معاصر لإستثمار المؤسسات الرياضية". أهداف الاراسة : التعرف على عوامل دراسات الجدوى كمدخل إدارى معاصر

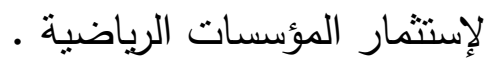
المنهج : إستخدم الباحث المنهج الوصفى • العينة : إثتملت عينة البحث على (0 • () فرد نم الإستعانة بـ( • منهم ليكونوا عينة الدراسة الإستطلاعية وبلغ حجم العينة (1) فرد من مسئولى الإدارة العليا

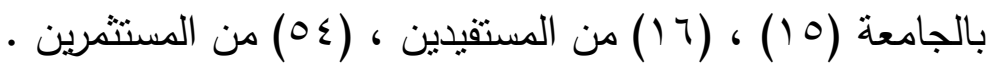


أدوات جمع البيانات : إستخدم الباحث المقابلة الشخصية ، الإستبيان . أهم النتائج :

من مجالات الإستشمار التى يمكن أن تحقق عائداً مالياً لإستاد الجامعة

حقوق البث التلفزيونى ، نادى صحى ، صالة مغلقة للألعاب الرياضية .

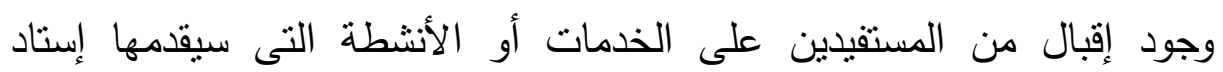
الجامعة كمشروع إستثمارى .

التمويل الحكومى مصدر غير كافى لتمويل إستاد الجامعة كمؤسسة رياضية .

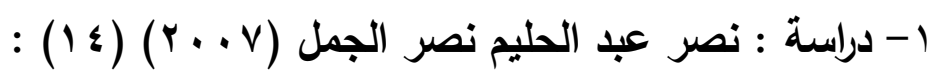

موضوع الدراسة : "دراسة تحليلية لتسويق المنشأت الرياضية بالقوات المسلحة ".

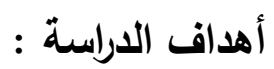

- دراسة وتحليل الأساليب التسويقية المقترحة والنماذج المعدول بها ـ

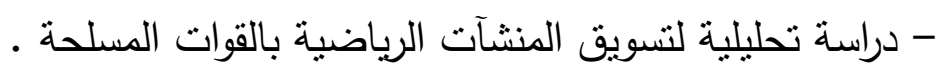
-المنهج : إستخدم الباحث المنهج الوصفى ( الدراسات المسحية ) . العينة : قام الباحث بتطبيث تجربة البحث على عينة عمدية عددها عه فرداً من 11 من رؤساء الأفرع ، ومدير نادى الجيش الرياضى ، وسكرنير عام الجهاز ،

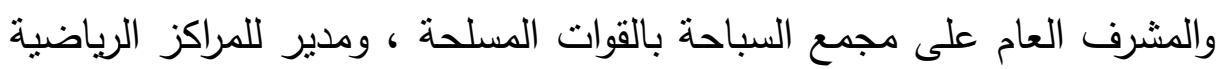

$$
\text { وسا قائداً للسرايا }
$$

أدوات جمع البيانات : المقابلة الثخصية وإستمارة الإسنبيان • (برايان ع -دراسة ديفرانس جاثكيو Defrance Jacque موضوع الاراسة : التسويق الرياضى عبر الإنترنت دراسة إستطلاعية عن مواقع

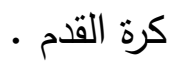


أهداف الدراسة : التعرف على رسالة مواقع كرة القدم فى إستراليا ونيوزلندا

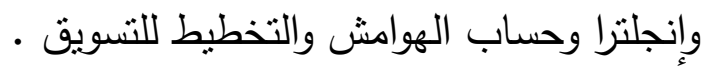

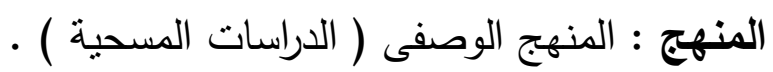
العينة : مسئولى مواقع الإنترنت والخبراء .

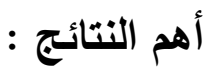

- إستخدام الإنترنت يعتبر وسيلة لتسويق الرياضة وآداة إدارية فعالة .

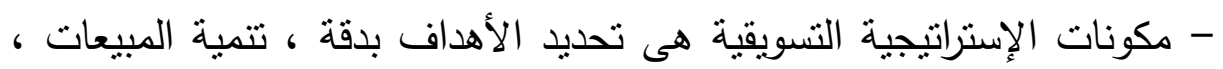
وجود تكنولوجيا جديدة فى الإتصالات وفى العلاقات العامة .

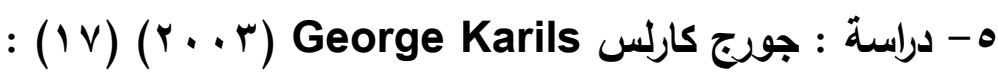
موضوع الدراسة :المدينة وإستراتيجية التسويق الرياضى: أثنيا ع . . ب ( دراسة حالة ). أهداف الاراسة : التعرف على ثأثثر إستضافة الألعاب الأوليمبية على السياحة ومناقنة بعض إستراتيجيات التسويق التى يجب على أثنيا إتباعها لكى تعظم الآثار الإيجابية للسياحة .

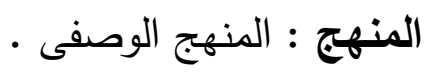
وقسمت الدراسة سوق الألعاب الأوليمبية إلى :

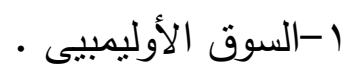

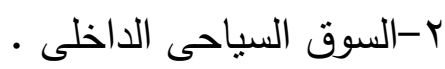

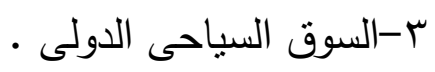

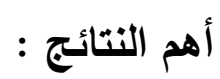
- إستضافة الألعاب اليونانية فى عام ؟ . . ب ينتج عنه آثار اقتصادية هامة للبونان

- زيادة معدل النمو فى الناتج المحلى وإتاحة وظائف جديدة وترويج المنطقة . - مصدر زيادة الأنشطة الإقتصادية هو المال القادم من السائحين الأجانب . 


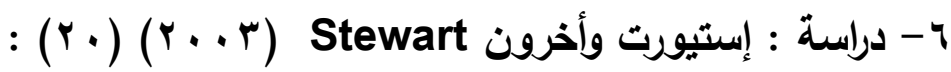

موضوع الاراسة : المستهلك الرياضى : أنواع متعددة ( وجهة نظر نقدية ) .

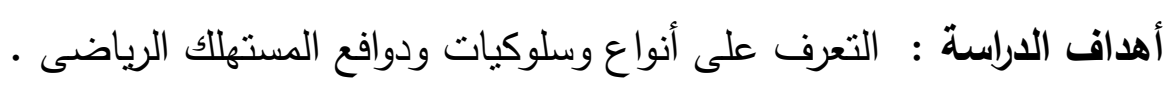

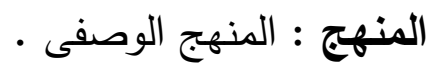

العينة : تتكون من المستهلكين رياضياً ومسئولى التسويق الرياضى .

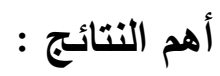

- إهتمام المسوقين الرياضيين تركيز قليلاًُعلى الإتجاهات الفلسفية الإجتماعية فقط . إجراعات البحث: منهج البحث:

استخدمت الباحثة المنهج الوصفي ( أسلوب الدراسات المسحية ) بخطواته وإجراءاته وذلك لمناسبته لتحقيق أهداف البحث مجتمع البحث:

يشمل مجتمع البحث مجالس إدارات (الأندية - الصالات الرياضية -

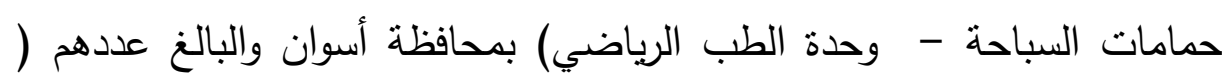

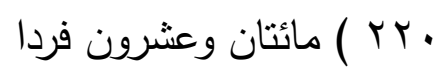

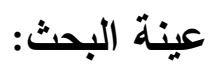

تم اختيار عينة البحث الطبقية العشوائية منبعض اعضاء مجلس إدارات الأندية والصالات وحمامات السباحة ووحدة الطب الرياضي علي عدد (ه) فرد. 


\section{توصيف مجتمع وعينة البحث}

جدول (1)

\begin{tabular}{|c|c|c|c|c|}
\hline |العينة الاستطلاعية & | ل العينة الأساسية & |مجتمع & فئات عينة البحث & \\
\hline ir & ro & 17. & 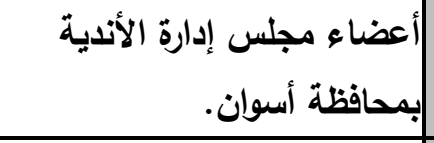 & 1 \\
\hline 0 & 9 & r. & |أعضاء مجلس إدارة الصالات & r \\
\hline$\wedge$ & ir & $r$. & |أعضاء مجلس إدارة حمامات & $r$ \\
\hline$\bullet$ & 9 & 1. & ألعضاء مجلس إدارة وحدة الطب & $\varepsilon$ \\
\hline$r$. & 00 & rr. & المجموع & \\
\hline$\% r$ & $\%$ ro & $\% 1 \ldots$ & النسبة المئوية \% & \\
\hline
\end{tabular}

جدول (r)

محاور استمارة استبيان لتسويق المنشآت الرياضية بمحافظة أسوان في صورتها المبلئية وعدد العبارات التي تنتمي إلي كل محور

\begin{tabular}{|c|c|c|}
\hline 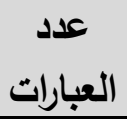 & المحــاور & م \\
\hline 11 & أسوان • الإمكانـات الماديـة والبشـرية كمصـدر مـن مصـادر التمويـل بمحافظـة & \\
\hline 1. & 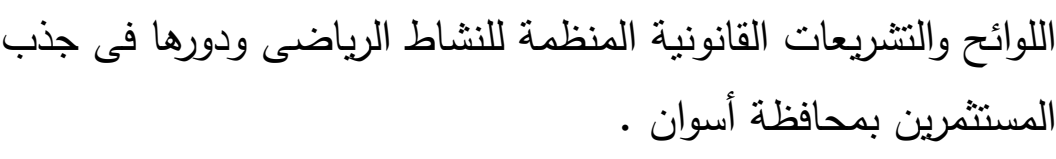 & $r$ \\
\hline
\end{tabular}




\begin{tabular}{|c|c|c|}
\hline 11 & النظام الإداري والرقابي داخل المنشآت الرياضية بمحافظة أسوان . & $\mid$ \\
\hline 9 & |بمحافظة أسوان. التسويق الحديثة ومدى ملاءمتها لتسويق المنشآت الرياضية & | \\
\hline 11 & |معوقات تسويق المنشآت الرياضية وسبل التغلب عليها بمحافظة & \\
\hline or & المجموع & \\
\hline
\end{tabular}

\section{جدول ( )}

النسبة المئوية لآراء الخبراء على عبارات الاستبيان فى صورته المبئية

$$
(q=\dot{0})
$$

\begin{tabular}{|c|c|c|c|c|c|c|c|c|c|c|c|}
\hline \multicolumn{11}{|c|}{ العبــــارات } & المحاور \\
\hline 1. & 9 & $\wedge$ & v & 7 & 0 & $\varepsilon$ & $r$ & r & 1 & رقم العبارة & \multirow{6}{*}{ 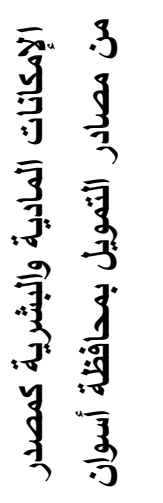 } \\
\hline 9 & $\varepsilon$ & $\wedge$ & $\varepsilon$ & $\wedge$ & 9 & v & 9 & $\wedge$ & 9 & تكرارها & \\
\hline \multirow[t]{4}{*}{$\% 1 \ldots$} & \multirow[t]{4}{*}{$\% \leq \varepsilon . \varepsilon$} & $\% \wedge \wedge . \wedge$ & $\% \leqslant \varepsilon . \varepsilon$ & $\% \wedge \wedge . \wedge$ & $\% 1 \ldots$ & $\% \vee \vee . \vee$ & $\% 1 \ldots$ & $\begin{array}{c}\wedge \wedge . \wedge \\
\%\end{array}$ & $\% 1 \ldots$ & المئوية & \\
\hline & & & & & & & & & 11 & رقم العبارة & \\
\hline & & & & & & & & & $r$ & تكرارها & \\
\hline & & & & & & & & & $\%$ \%r.r & المئوية & \\
\hline ri & $r$. & 19 & 11 & IV & 17 & 10 & $1 \leqslant$ & ir & Ir & رقم العبارة & ఫ \\
\hline$\wedge$ & 9 & 9 & $\wedge$ & $\varepsilon$ & 0 & v & 9 & $\wedge$ & 9 & تكرارها & ] \\
\hline$\% \wedge \wedge . \wedge$ & $\% 1 \ldots$ & $\% 1 \ldots$ & $\% \wedge \wedge . \wedge$ & $\% \leq \varepsilon . \varepsilon$ & $\% \bullet 0.0$ & $\% \vee \vee . \vee$ & $\% 1 \ldots$ & $\begin{array}{c}\wedge \wedge . \wedge \\
\%\end{array}$ & $\% 1 \ldots$ & المئوية & 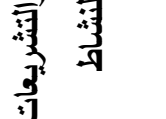 \\
\hline r & $r$. & rq & $r \wedge$ & $r V$ & rq & ro & $r \varepsilon$ & rT & rr & رقم العبارة & $\bar{a}$ \\
\hline$v$ & $\wedge$ & V & $\wedge$ & 9 & $\wedge$ & V & $\varepsilon$ & $\wedge$ & 0 & تكرارها & \\
\hline
\end{tabular}




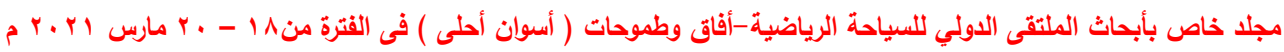

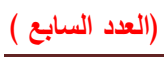

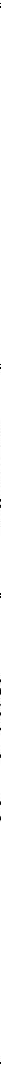

يتضح من جدول ( r ) أن النسبة المئوبة للآراء الخبراء حول عبارات الاستبيان نتراوح ما بين يوضح معامل الارتباط بين درجة كل عبارة من عبارات الاستبيان

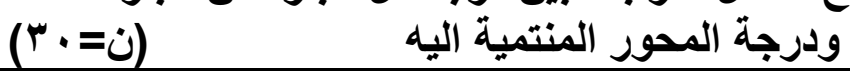

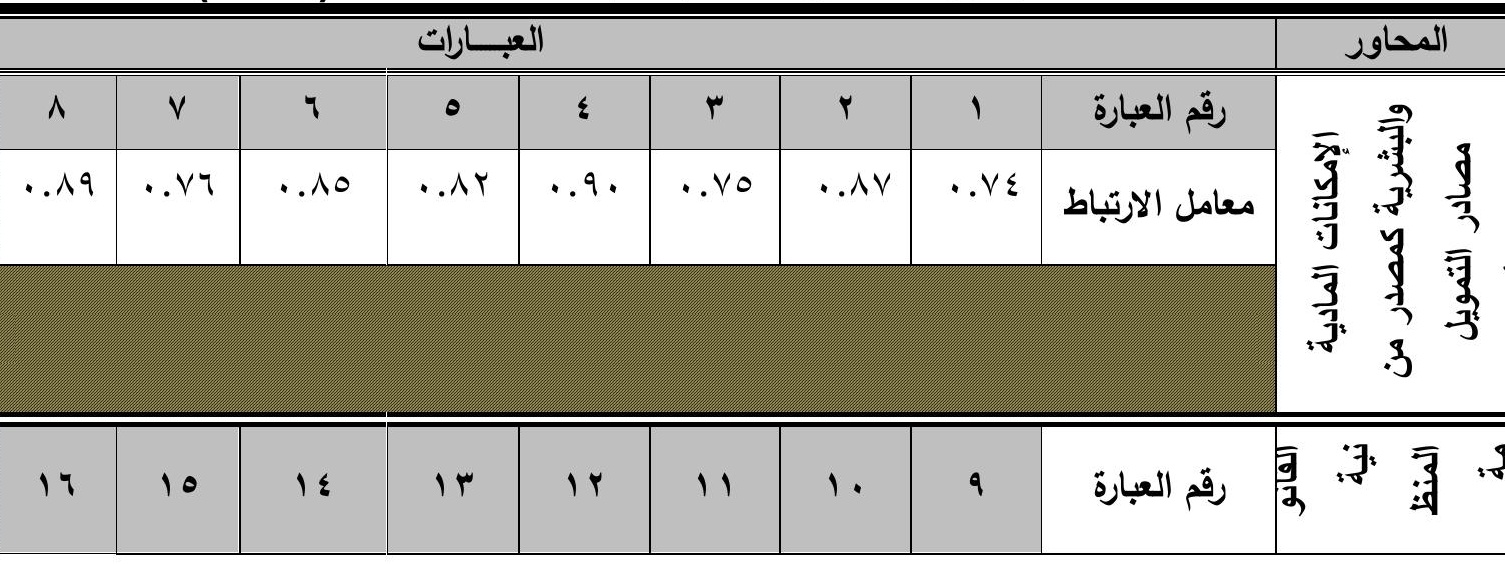




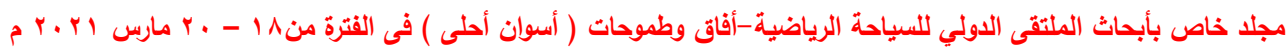

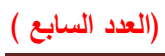

\begin{tabular}{|c|c|c|c|c|c|c|c|c|c|c|}
\hline &..$\vee 9$ &..$\vee 9$ & $\because V V$ &..$V Y$ & $\because v_{0}$ &.$\wedge \varepsilon$ &. .9 . & $\because \vee \wedge$ & معامل الارتباط & \\
\hline ro & $r \varepsilon$ & rT & YY & $r_{1}$ & $r$. & 19 & 11 & IV & رقم العبارة & \multirow{2}{*}{ 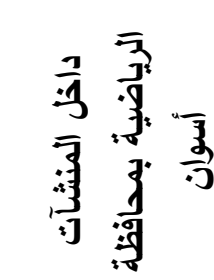 } \\
\hline 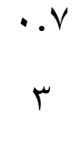 &. .11 &..$V V$ &.$\wedge 1$ &. .11 & $\cdots 9$ &.$V Y$ &..$\wedge 7$ &..$V Y$ & معامل الارتباط & \\
\hline & & & $r$ & $r$. & rq & $r \wedge$ & $r V$ & Yq & رقم العبارة & \multirow{2}{*}{ 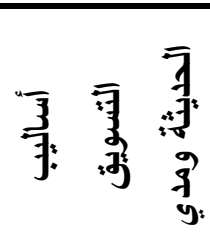 } \\
\hline & & & $\because 9$. & . . & $\because \vee q$ &. Vo &..$V \varepsilon$ & $\because \vee \wedge$ & معامل الارتباط & \\
\hline$\varepsilon$. & rq & rs & $r v$ & rq & ro & $r \varepsilon$ & r & rr & رقم العبارة & \multirow{2}{*}{ 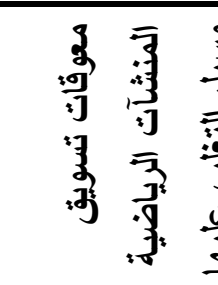 } \\
\hline$\cdot V T$ &. .9 . &. .70 & .10 &..$\wedge 9$ & $\cdot . \wedge \wedge$ & .19 &. .19 & .10 & معامل الارتباط & \\
\hline
\end{tabular}

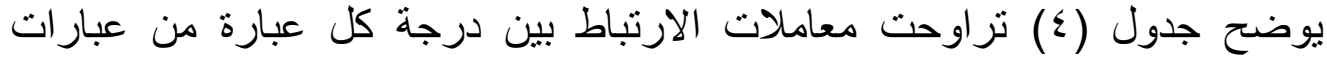
الاسنبيان ودرجة المحور المنتمية إلية ما بين ( 10.

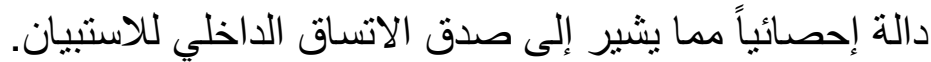




$$
\text { جدول (•) }
$$

معامل الارتباط بين مجموع درجات كل محور

والارجة الكلية للاستبيان

\begin{tabular}{|c|c|c|}
\hline معامل & المحاور & r \\
\hline$\% .9 r$ & 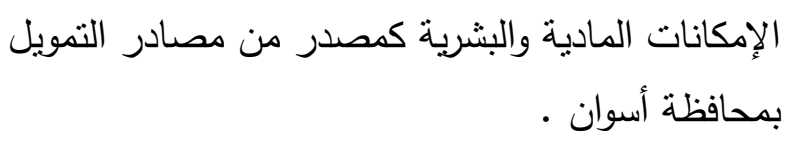 & 1 \\
\hline$\% \cdot . \wedge \wedge$ & ودورها فى جذب اللوائح والتشريعات القانونية المنظمة للنشاط الرياضى & $r$ \\
\hline$\% .90$ & بمافظة أسوان • الإداري والرقابي داخل المنشآت الرياضية & $r$ \\
\hline$\% \cdot . q$. & 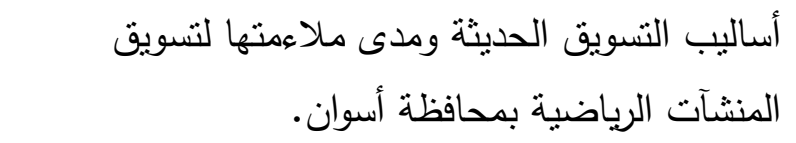 & $\varepsilon$ \\
\hline$\% .94$ & بمحافظة أسوان. تسويق المنشآت الرياضية وسبل التغلب عليها & 0 \\
\hline
\end{tabular}

$$
\text { ققيمة ر الجدولية عند مستوي دلالة ه. . =0ب. • }
$$

يوضح جدول ( 0 ) نراوحت معاملات الارنباط بين مجموع درجات كل

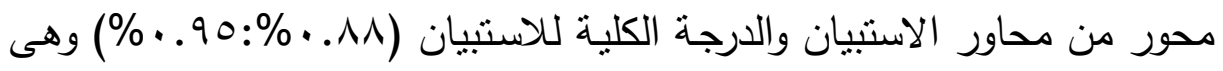
معاملات ارتباط دالة إحصائيا مما يثير إلى الاتساق الداخلي للاستبيان ، أن أن الاستبيان يتمتع بدرجة مقبولة من الصدق • 


\section{بالثبات :}

للتأكد من ثبات المقياس قامت الباحثة باستخدام عن طريق معامل ألفا لكرونباخ وذللك بتطبيقها على عينة قوامها ( ب) ثلاثثن فرداً من مجتمع البحث ومن خارج العينة الأصلية ، والجدول التالي

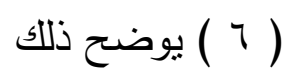

\section{جدول ( 7 ( )}

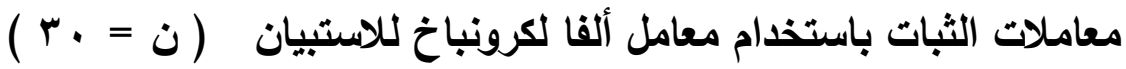

\begin{tabular}{|c|c|c|}
\hline معامل & الاستبيان & r \\
\hline$\% \cdot .91$ & أسوان • الإمكانات المادية والبشرية كمصدر من مصادر التمويل بمحافظة & । \\
\hline$\% \cdot .91$ & 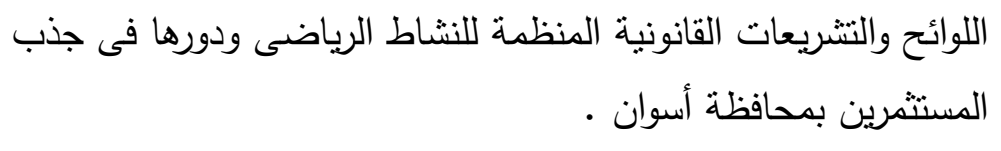 & r \\
\hline$\% \cdot .94$ & النظام الإداري والرقابي داخل المنشآت الرياضية بمحافظة أسوان • & r \\
\hline$\% \cdot .9 r$ & بمحافظة أسوان. ألسويق الحديثة ومدى ملاءمنها لتسويق المنشآت الرياضية & $\varepsilon$ \\
\hline$\% \cdot .9$. & معوقات تسويق المنشآت الرياضية وسبل التظلب عليها بمحافظة & 。 \\
\hline$\% .91$ & الارجة الكلية & \\
\hline
\end{tabular}




\section{عرض النتائج وتفسيرها ومناقشتها}

عرض نتائج وتفسير ومناقشة المحور الأول الإمكانات المادية والبشرية ومنية

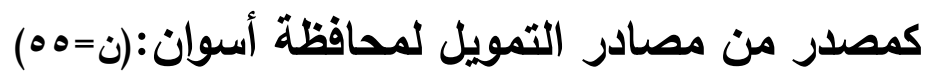

\begin{tabular}{|c|c|c|c|c|c|c|}
\hline \multirow[b]{2}{*}{ كاץ } & \multirow[b]{2}{*}{ 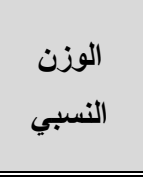 } & \multirow{2}{*}{ 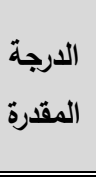 } & \multicolumn{3}{|c|}{ درجة الاستجابة } & \multirow[b]{2}{*}{ 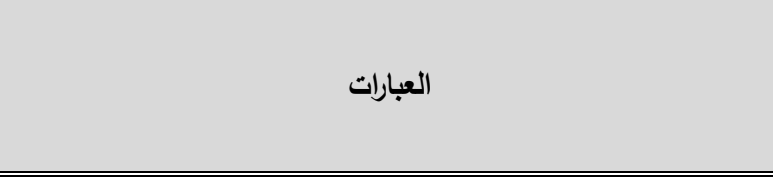 } \\
\hline & & & موافير & الى حـا & 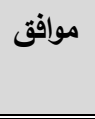 & \\
\hline $70 \varepsilon .11$ & $\%$ \% 10 & TrE & 1 & ra & 10 & ومستوى الكوادر الفنية بإدارة النشاط الرياضى يتناسب مع أعداد \\
\hline $94 \cdot . T V$ & $\%$ \%.r. & $1 \leqslant 9$ & $\varepsilon$ & $\wedge$ & $\varepsilon r$ & أسوان. أفراد متخصصون على صيانة المنشآت الرياضية بمحافظة \\
\hline rव५.TV & $\% \vee \cdot .9$. & $11 \mathrm{~V}$ & 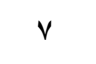 & $r \varepsilon$ & $1 \varepsilon$ & تخدم المنشآت الرياضية المجتمع الخارجى المحيط بالمحافظة \\
\hline TYE.TV & $\% \wedge . .7$. & Irr & 1. & ir & r & 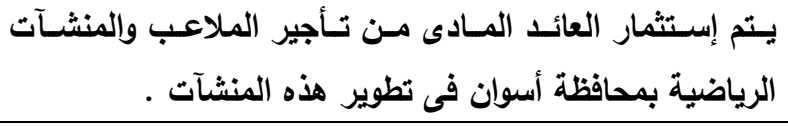 \\
\hline Y. ¿.TV & $\%$ \%v.०v & IrN & ir & ir & r. & 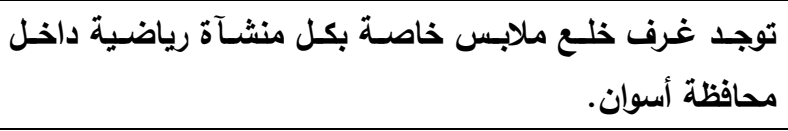 \\
\hline VVA.TV & $\% \wedge \wedge . £ \wedge$ & $1 \leqslant 4$ & ० & 9 & « & المنافسات الرسمية ل. لـندة الرياضيين أثناء فترة إعداد الفرق وإستضافة \\
\hline rT..TV & $\% ч . .7$. & $1 \ldots$ & 11 & rq & $\wedge$ & كافية ومطابقة للمواصفات الألقانونية داخل . \\
\hline 纟OY.TV & $\%$ o.r. & $\Delta r$ & rı & r & 1 & 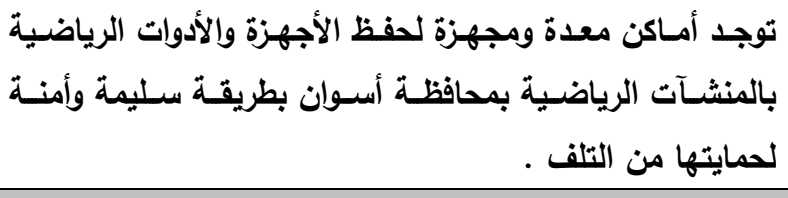 \\
\hline & $\% \vee \leqslant . r \leqslant$ & $9 \wedge$. & & & & المجموع \\
\hline
\end{tabular}

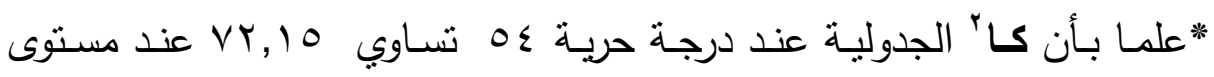

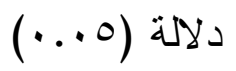

يتضح من الجدول (V) أن أعلى عبارة (Y)"'" يقوم أفراد متخصصون على

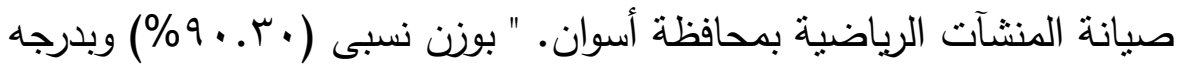

مقدرة (9 § ()، بينما جاءت أقل عبارة (^) " توجد أماكن معدة ومجهزة لحفظ 
الأجهزة والأدوات الرياضية بالمنشآت الرياضية بمحافظة أسوان بطريقة سليمة

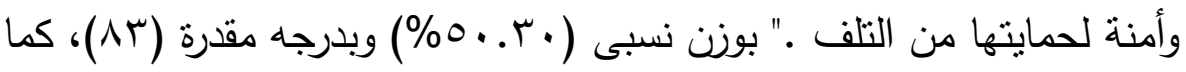
كان الوزن النسبي لآراء عينة البحث في عبارات الاستبيان لمحور (الإمكانات

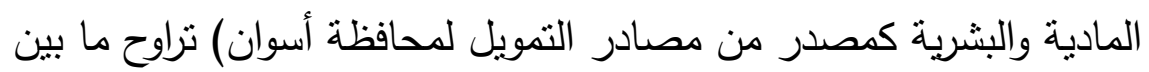

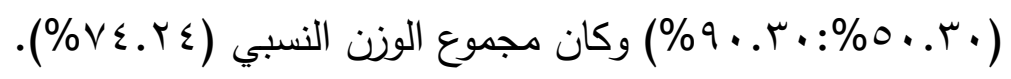

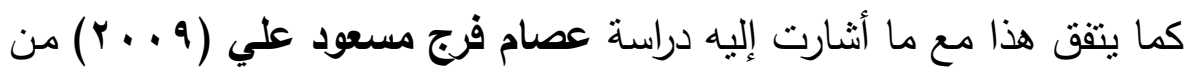

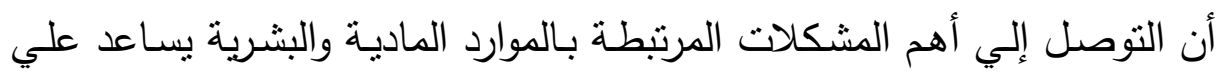

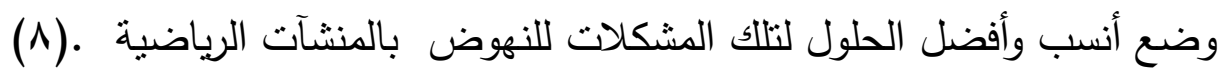
كما يتفق هذا مع ما تشير إليه دراسة جورج كارلس George Karils

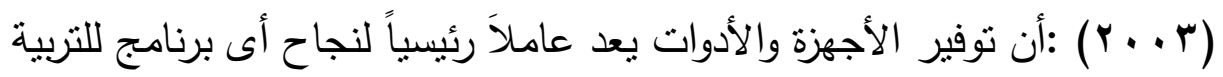
الرياضية وذللك لأنه يستحيل أن يؤدى نوع من الأنشطة الرياضية فى غياب الأجهزة والأدوات الخاصة بهذا النشاط ، لذلك تعتبر الأجهزة والأدوات عنصراً هاماً لتحقيق أهداف التربية الرياضية فى مختلف مجالاتها ـ (9V:IV) كما ترى الباحثة أنه يوجد قصور ونقص واضـح فـى معظم الإمكانـات الماديـة والبشرية مما سيكون لهو تأثير واضـح وكبير على تسويق المنشآت الرياضية بكافة فروع المنشآت الرياضية بالمحافظة.

عرض نتائج وتفسير ومناقشة المحور الثاني : اللوائح والتشريعات القانونية المنظمة للنشاط الرياضي ودورها فى تسويق المنشآت الرياضية بمحافظة أسوان: 
جدول (^)

الارجة المقدرة والوزن النسبي لاستجابات عينة البحث في المحور الثاني

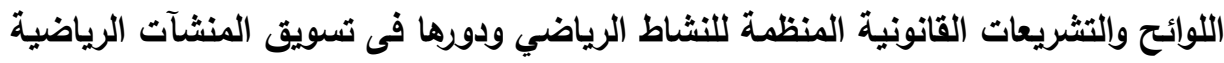
بمحافظة أسوان: - افي

$(\theta 0=\dot{0})$

\begin{tabular}{|c|c|c|c|c|c|c|c|}
\hline \multirow[b]{2}{*}{ الترتيب } & \multirow[b]{2}{*}{ كا' } & \multirow[b]{2}{*}{ 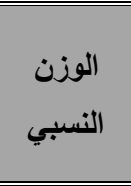 } & \multirow{2}{*}{ 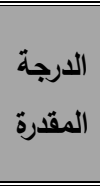 } & \multicolumn{3}{|c|}{ درجة الاستجابة } & \multirow[b]{2}{*}{ العبارات } \\
\hline & & & & غوافي & الى حـ & موافق & \\
\hline 1 & rr..TV & $\%$ \%.r & 1.1 & 17 & rr & v & 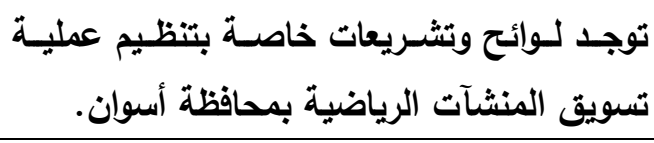 \\
\hline$\wedge$ & $r \leqslant Y . T V$ & $\%$ \%..०q & 91 & 19 & rq & v & 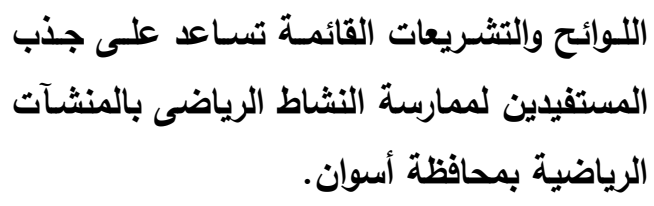 \\
\hline r & $111.7 \mathrm{~V}$ & $\% \vee \wedge .1 \wedge$ & ira & 1. & 17 & rq & 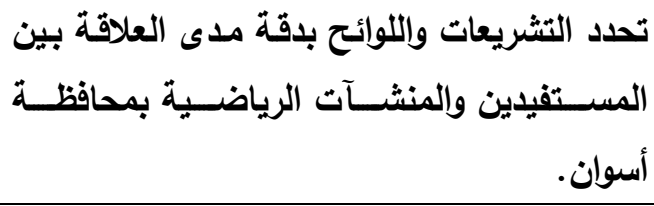 \\
\hline$\bullet$ & rqะ.7V & $\%$ \%. ะ & Ar & rr & iv & 。 & 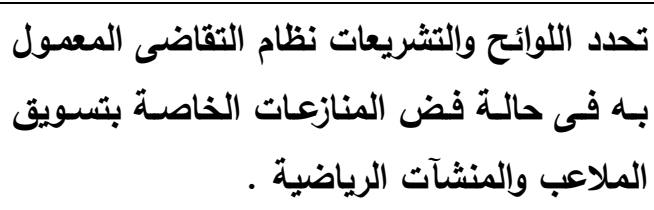 \\
\hline$r$ & Y. ¿.TV & \%vv.०v & $1 r \Lambda$ & ir & ir & $r$. & تالتسويق المنشآت القوانين واللوائح والتشريعات في عملية \\
\hline 1 & $r .4 .7 V$ & $\% \wedge \Lambda . Y 1$ & צ & $\wedge$ & 10 & rr & 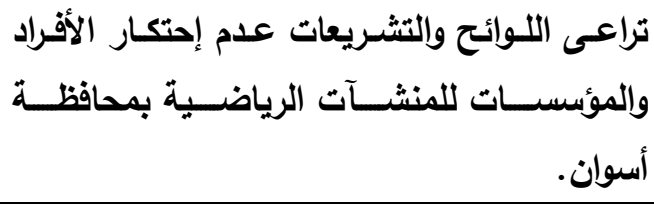 \\
\hline$v$ & 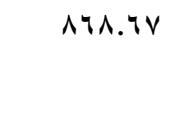 & $\% \leqslant 1 . \wedge 1$ & 79 & $\leqslant 1$ & $1 \varepsilon$ & - & 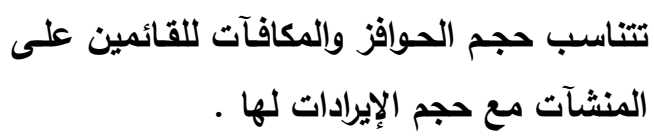 \\
\hline$\varepsilon$ & Dor.TV & $\% \vee \leqslant .0 \leqslant$ & IrT & $r$ & די & 17 & توجــ لائحسة ماليـة لتـأجير الملاعب والمنشـآت \\
\hline
\end{tabular}




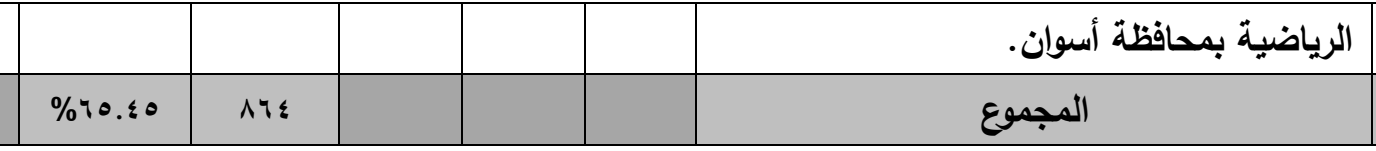

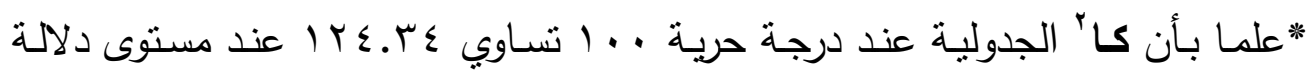

$$
(\cdot .0)
$$

يتضـح مـن الجدول (^) أن أعلى عبارة (†)" تراعى اللـوائح والتتـريعات عدم

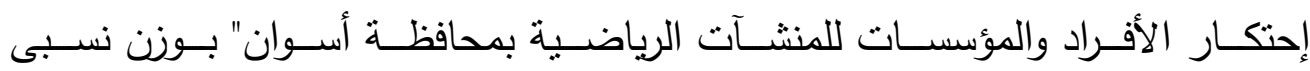

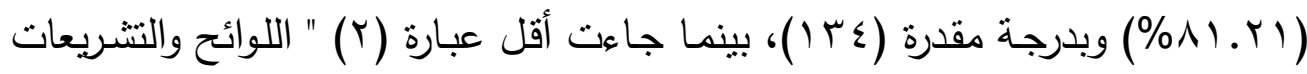
القائمـة تسـاعد على جذب المستقيدين لممارسـة النشاط الرياضـى بالمنشـآت الرياضية بمحافظة أسوان." بوزن نسبى (9.09\%\%) وبدرجة مقدرة (9^)، كما كان الوزن النسبي

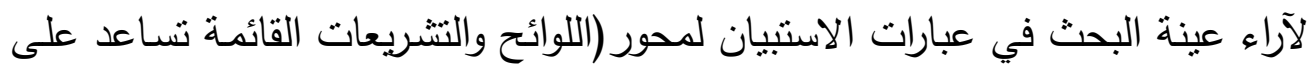
جذب المستقيدين لممارسة النشاط الرياضى بالمنشآت الرياضية بمحافظة أسوان) تراوح

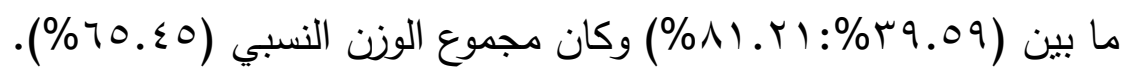

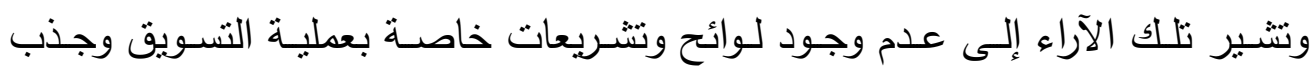

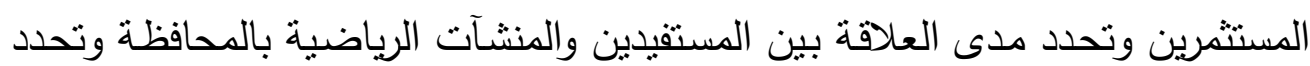
نظم التقاضـى والحـوافز والمكافـأت وتراعى عدم إحتكـار الأفراد للمنشـآت الرياضـية

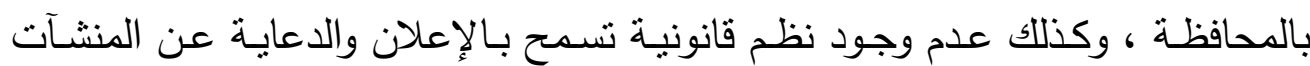

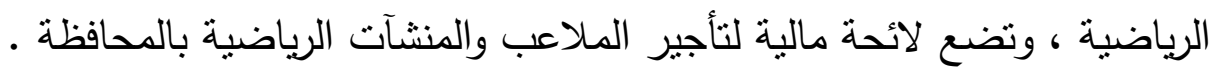

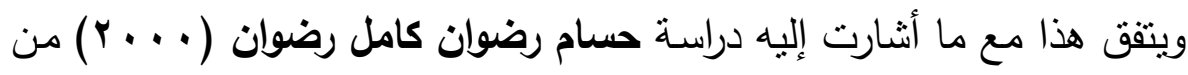
ضـرورة تطوير التشـريعات القانونيـة ووضـع نظـام قانونى ينظم العمل فى ظل إتجـاه

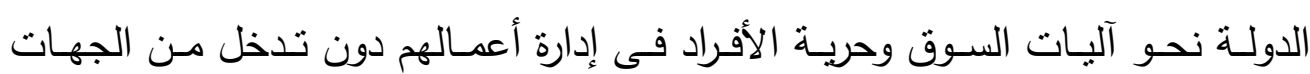

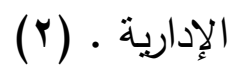


وترى الباحثة أنه يجب أن تكون للمنشآت الرياضية تشريعات ولوائح قانونية

تساهم فى عملية التسويق للمنشآت الرياضية ، كما يجب أن يقوم متخصصون بتولى عملية الدعاية التسويقية للعمل على جذب المستقيدين والمساهمين - الخ •

عرض نتائج وتفسير ومناقثة المحور الثالث النظام الإداري والرقابي داخل المنشآت

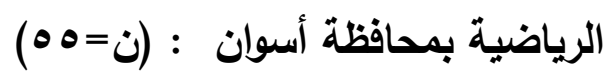

جدول (9)

\begin{tabular}{|c|c|c|c|c|c|c|c|}
\hline \multirow[b]{2}{*}{ الترتيب } & \multirow[b]{2}{*}{ كا' } & \multirow{2}{*}{ 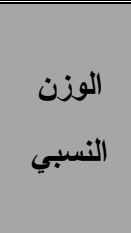 } & \multirow{2}{*}{ المقدرة } & \multicolumn{3}{|c|}{ درجة الاستجابة } & \multirow[b]{2}{*}{ العبارات } \\
\hline & & & & غير & 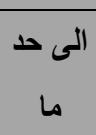 & موافق & \\
\hline - & $1 \leqslant \& .7 V$ & V५. 94 & IrV & 1. & 11 & rV & وفقير العمل بالمنشآت الرياضية بمحافظة أسوان \\
\hline 9 & VVA.TV & $\% 0 . .9$. & $\Lambda \varepsilon$ & \&1 & 9 & 0 & 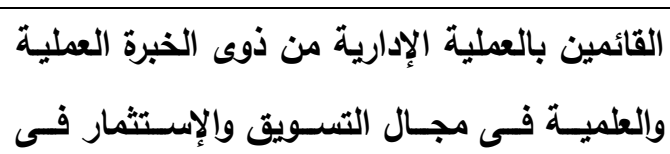 \\
\hline v & & \%ฯV.AV & $11 r$ & 11 & $r v$ & $v$ & في مجال الدر فى التظيم الإداري بالمنشات متخصصون \\
\hline$\wedge$ & $\varepsilon \ldots .7 V$ & \%०r.lr & 14 & rq & $Y V$ & r & التياضب قدرات الهيكل التنظيمى الحالى للمنشآت \\
\hline$\varepsilon$ & 11.TV & \%४v.०v & IrA & $1 \varepsilon$ & 10 & צ & 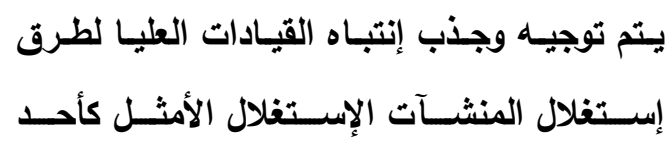 \\
\hline
\end{tabular}




\begin{tabular}{|c|c|c|c|c|c|c|c|}
\hline & & & & & & & المجالات الهامة فى التطوير \\
\hline r & rr..TV & \%จq.rq & $|r|$ & $\wedge$ & 11 & rq & 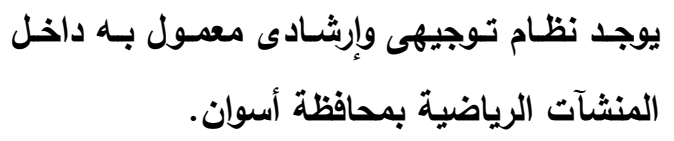 \\
\hline 7 & 9Y.TV & $\% \vee \leq .0 \leq$ & Irr & ir & 17 & Y & 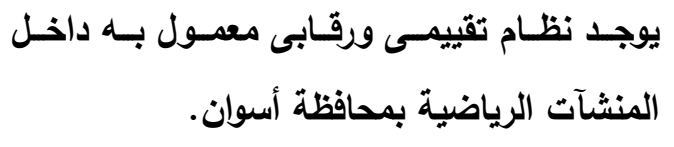 \\
\hline 1 & rrs.TV & $\% \wedge r . \&$ r & 4r & 0 & 19 & $r$ & 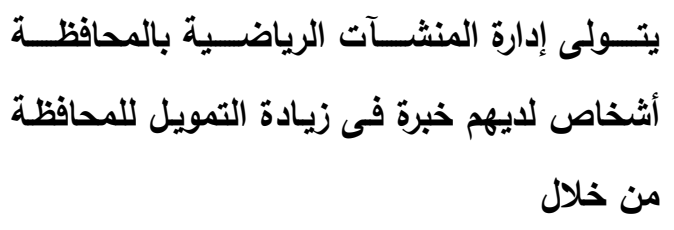 \\
\hline$r$ & $r \ldots T V$ & $\% \vee \wedge . \mid \wedge$ & 149 & v & rr & Y & 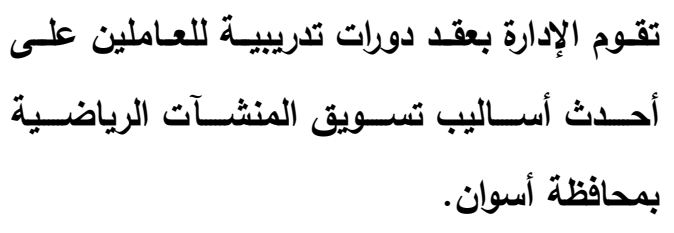 \\
\hline & & $\% \vee 1.11$ & 1.07 & & & & 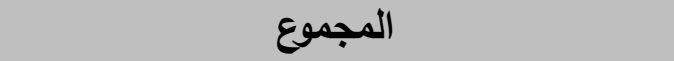 \\
\hline
\end{tabular}

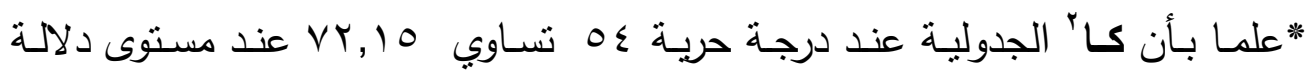

$$
(\cdot .0)
$$

يتضـح مـن الجدول (9) أن أعلى عبارة (^ ) " يتولى إدارة المنشـآت الرياضية بالمحافظة أنثخاص لديهم خبرة فى زيادة التمويل للمحافظة من خلال تسويق المنشآت

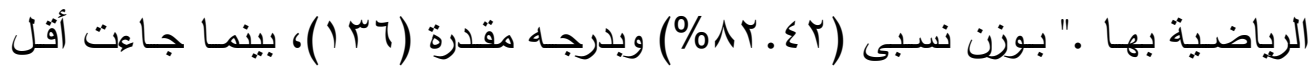
عبـارة (Y) " القائمين بالعمليـة الإداريـة مـن ذوى الخبـرة العمليـة والعلميـة فى مجـال التسـويق والإسـتمار فى المجال الرياضـى ."بـوزن نسبى ( • . • \%\%) وبدرجهـ مقدرة (^^)، كما كان الوزن النسبي لآراء عينة البحث في عبارات الاسنبيان لمحور ( النظام 


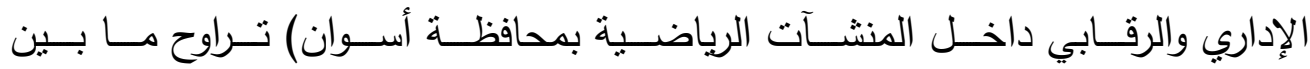

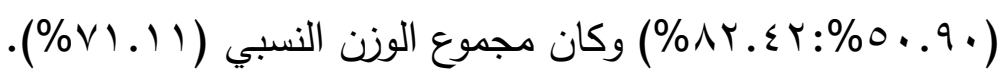

ويتفق هذا مـع دراسـة محمد رجب أحمد جبريـل (1 ( . . التى وضحت مدى تأثنير غياب الكوادر الإدارية المؤهلة والمتخصصـة فى وضـع الخطط التسويقية للمنتج الرياضى للعمل على تحقيق أهداف المنشأة بما يتتاسب مع إمكانياتها ( ( ) .

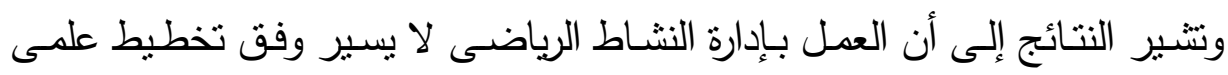

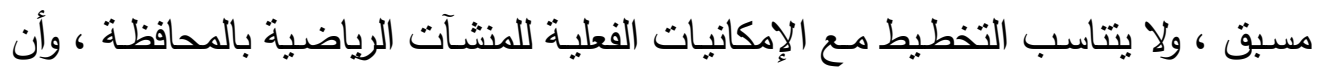

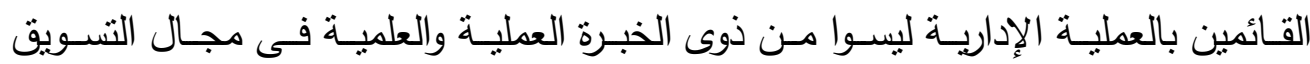

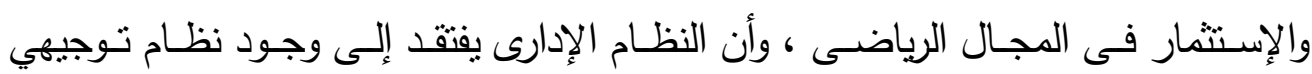
وتقييمي ورقابى معمول به. وترى الباحثة أهمية الدورات التدريبية التى تساعد على خلق كوادر إدارية قادرة

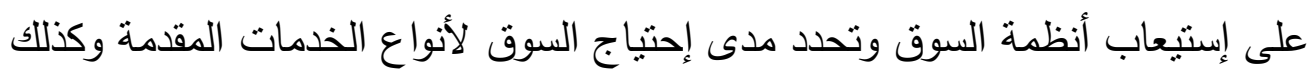

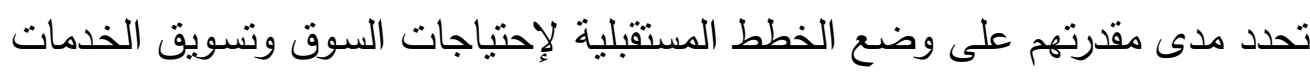

وفى هذا يتفق كلاً من دراسة جيونج هاك لى Jeoung Haklee ( J . J ( ) : على أن المنشـأة الرياضية تحتاج إلى الإدارة الجيدة التى تديرها على أسس وقواعد علمية وفنية سليمة ، وتسطيع تسويقها وإستغلالها فى الحصول على مصادر تموبل الردايل $\cdot(1 \wedge)$

عرض نتائج وتفسير ومناقثـة المحور الرابـع أسـاليب التسـويق الحديثة ومدى ملاعمتها لتسويق المنشآت الرياضية بمحافظة أسوان: 


\section{جدول (1.)}

الدرجة المقدرة والوزن النسبي لاستجابات عينة البحث في المحور الرابع أساليب التسويق الحديثة ومدى ملاعمتها لتسويق المنشآت الرياضية بمحافظة

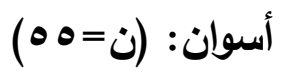

\begin{tabular}{|c|c|c|c|c|c|c|c|}
\hline \multirow[b]{2}{*}{ كا' } & \multirow[b]{2}{*}{ الوزن النسبي } & \multirow{2}{*}{ 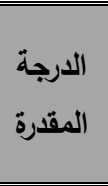 } & \multicolumn{3}{|c|}{ درجة الاستجابة } & \multirow[b]{2}{*}{ العبارات } & \multirow[b]{2}{*}{ p } \\
\hline & & & موافير & 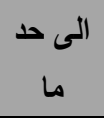 & موافق & & \\
\hline AT. & \%vr.qr & Irr & 11 & r & rr & 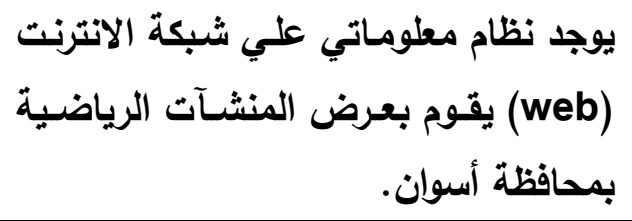 & 1 \\
\hline $\begin{array}{l}V V \\
\Lambda .7 \\
V\end{array}$ & $\% \leftleftarrows \leqslant . \wedge \varepsilon$ & $v \varepsilon$ & « & 9 & 0 & 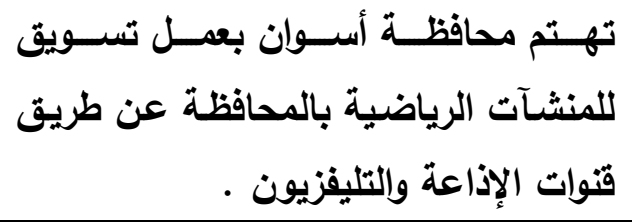 & r \\
\hline $\begin{array}{l}\text { or } \\
.7 \\
\text { v }\end{array}$ & \%०r.qr & 19 & $r$. & 14 & 9 & 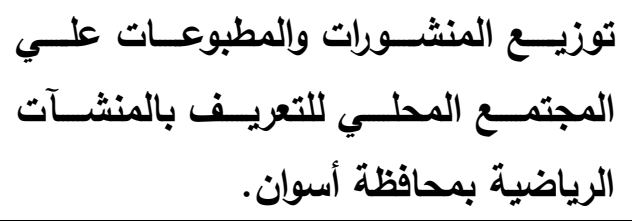 & $r$ \\
\hline $\begin{array}{l}\varepsilon \\
.7 \\
v\end{array}$ & $\% \circ v . \circ v$ & 90 & rq & ir & $1 \varepsilon$ & 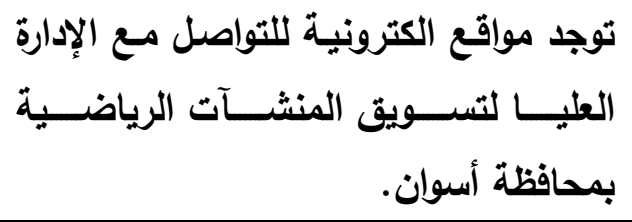 & $\varepsilon$ \\
\hline Th. & \%ั4. 94 & $\because$ & $\leq 9$ & 1 & - & 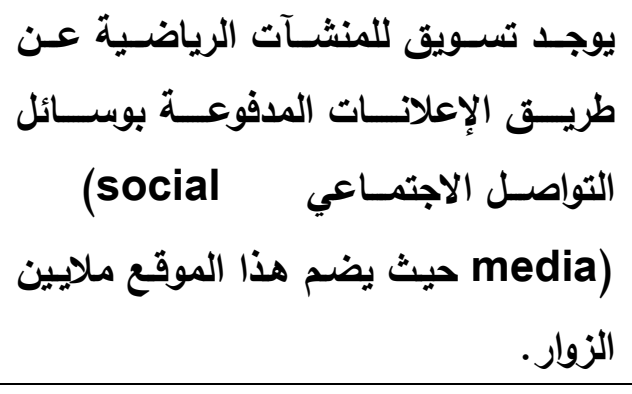 & 0 \\
\hline 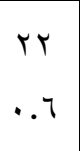 & $\%$ \% \&.r 4 & Vr & $\varepsilon$ & ir & $r$ & 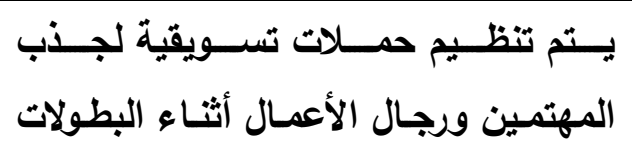 & 7 \\
\hline
\end{tabular}




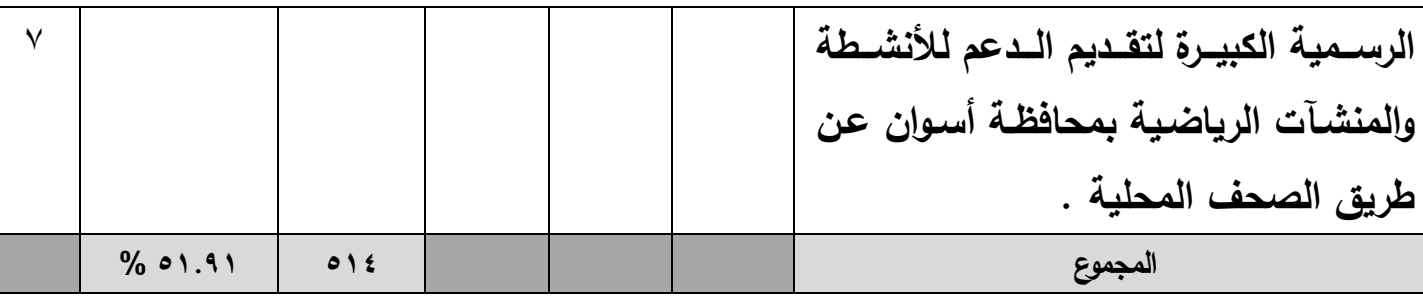

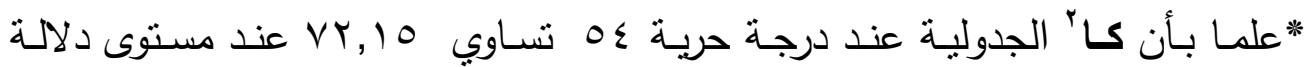
$(\cdot .0)$ يتضـح مـن الجدول (· ( ) أن أعلى عبـارة ( ()" يوجد نظـام معلومـاتي علـي شـبكة

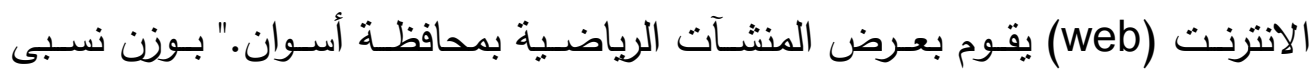

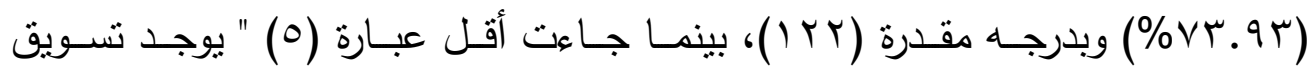
للمنشـآت الرياضية عن طريق الإعلانـات المدفوعة بوسائل التواصل الاجتمـاعي (social media) وبدرجه مقدرة (آ)، كما كان الوزن النسبي لآراء عينة البحث في عبارات الاستبيان

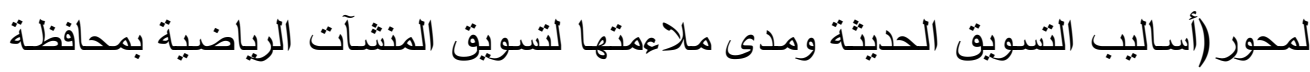

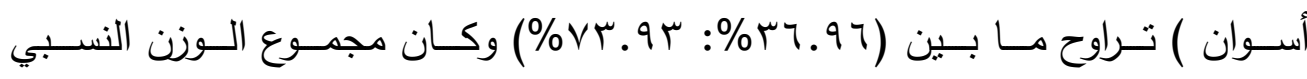
.$(\% 01.91)$

أنثـارت النتائج إلى أن إدارة المنشـآت الرياضية لا يتوفر لـديها نظـام معلومـاتى

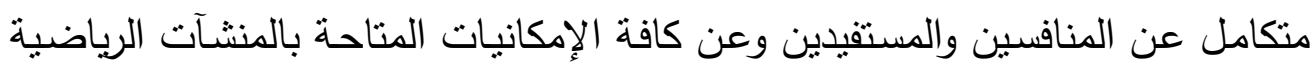

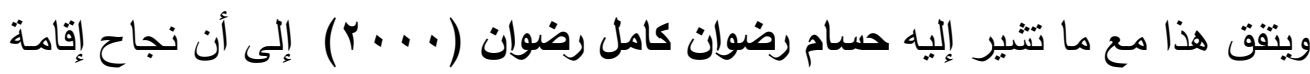

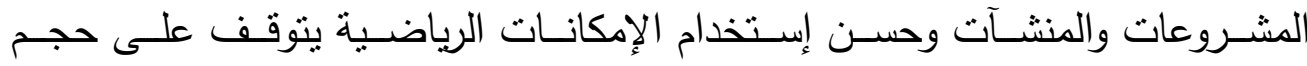

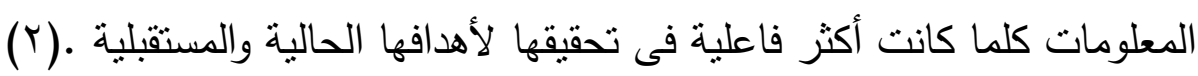
وكـللك أثــارت النتـائج إلـى أن الإدارة لا تعتمـد فـى إتخـاذ قـرارات التطــوير

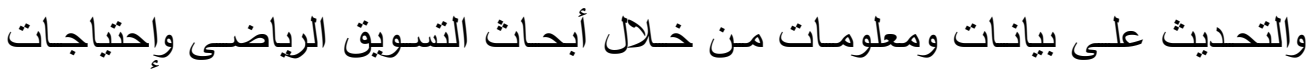

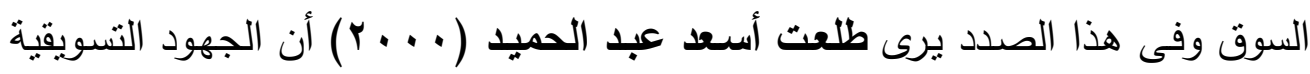
تبدأ عادة بإكتساب الحاجات والرغبات التى لم تشبع بعد والتى يمكن للمنشأة بإمكانياتها 
الحالية والمستقبلية من إشباعها فى ظل ظروف البيئة المحيطة ، ويتطلب ذلك إعادة إجراء بحوث منتظمة بغرض تصميم وتقديم المنتجات التى تتتاسب مع حاجات العملاء

$$
(Y): T) \text {. }
$$

عرض نتائج وتفسير ومناقشة المحور الخامس معوقات تسويث المنشأت الرياضية وسبل التظلب عليها بمحافظة أسوان:

$$
\text { جدول (11) }
$$

الارجة المقدرة والوزن النسبي لاستجابات عينة البحث في المحور الخامس

\begin{tabular}{|c|c|c|c|c|c|c|c|}
\hline \multirow[b]{2}{*}{ sil } & \multirow[b]{2}{*}{ النسبي } & \multirow{2}{*}{ اللدرجة } & \multicolumn{3}{|c|}{ لدرجة الاستجابة } & \multirow[b]{2}{*}{ 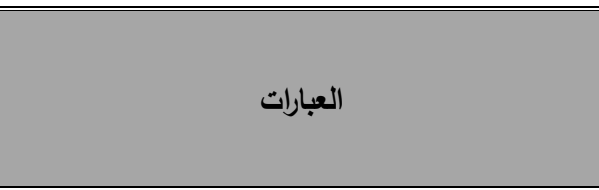 } & \multirow[b]{2}{*}{ s } \\
\hline & & & غوافير & الى حد & موافق & & \\
\hline THT.TV & $\% \vee 4.94$ & IrV & 7 & r4 & rr & توجد كفاية بأعمال التشغيل والصيانة. & 1 \\
\hline IYA.TV & \%vr.lr & 119 & 1. & r & 19 & 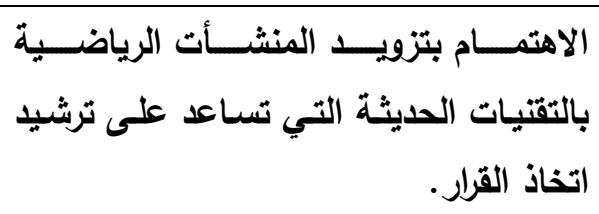 & r \\
\hline rqะ.TV & $\% \wedge r . t r$ & irs & - & iv & r & 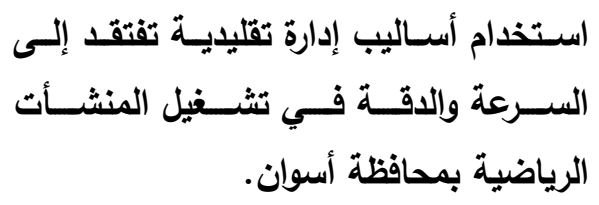 & $r$ \\
\hline$T \varepsilon \cdot . T V$ & $\% \wedge \diamond . \leqslant 0$ & $1 \leqslant 1$ & $\wedge$ & $\wedge$ & rq & 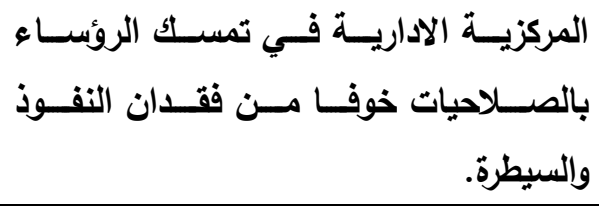 & $\varepsilon$ \\
\hline r. ¿.TV & $\% \wedge 1 . r 1$ & צr & $\wedge$ & 10 & rr & 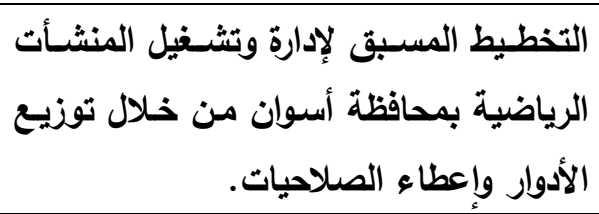 & 。 \\
\hline$\Lambda \leq .7 V$ & $\% \vee \leqslant .0 \leqslant$ & irr & ir & 11 & ro & اختيار شركات رعاية لها قدرة على التسويق & $\uparrow$ \\
\hline
\end{tabular}

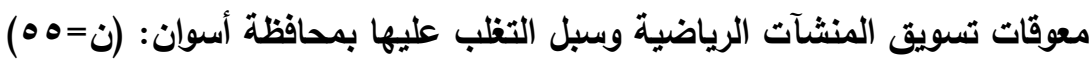




\begin{tabular}{|c|c|c|c|c|c|c|c|}
\hline & & & & & & الرياضي. & \\
\hline$\wedge \Lambda .7 \vee$ & $\% \vee \leqslant .0 \leqslant$ & IrT & 11 & r. & $r \varepsilon$ & أسوان الدخل المالي للمنشأت الضافية للأعضاء الجداضد لزيادة بمدافظة & $v$ \\
\hline$r T \cdot . T V$ & \%४q.rq & iri & $\wedge$ & 11 & rq & لضمان عدود رقابـة صـارمة على الأمسال الداخليـة & $\wedge$ \\
\hline Y...TV & $\% ч \leq . Y \leqslant$ & 1.4 & צ' & $v$ & rr & تقويم أداء العاملين بشكل دائم. & 9 \\
\hline & \%४ ..9. & $11 \leqslant r$ & & & & المجموع & \\
\hline & $\%$ \%., & ؛004؛ & & & & المجموع الكلي للاستمارة & \\
\hline
\end{tabular}

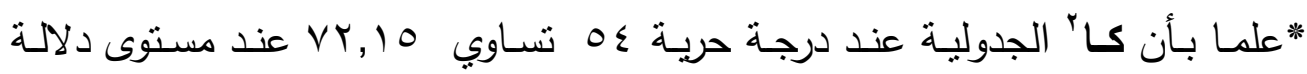
$(\cdot .0)$

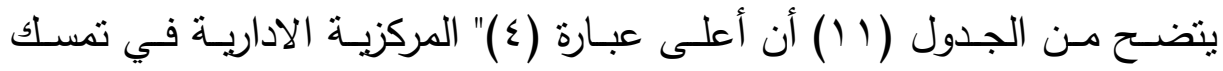

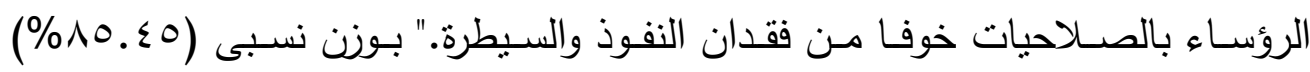

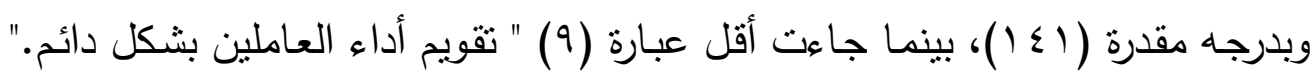

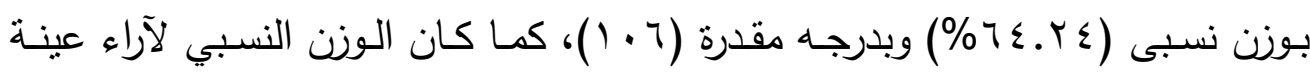
البحث في عبارات الاستبيان لمحور (معوقات تسويق المنشآت الرياضية وسبل التغلب

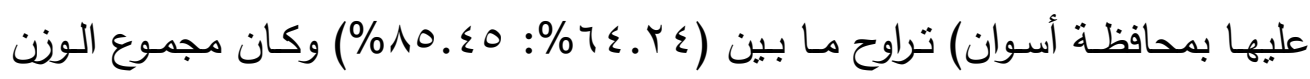

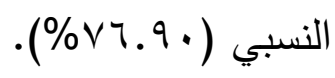

وتوضتح الباحثة أنه أصبح التسويق علماً يستند إلى اسس وقواعد علمية وان التسويق الرياضي هو احد الانشطة المصممة لمقابلة احتياجات ورغبات المستهلك الرياضي من خلال عمليات المشاركة وفي هذا الاطار ظهرت مفردات وموضوعات لها علاقة بهذا الخصوص ومنها ما هو اساس للتسويق الرياضي لكي يتحقق النجاح .

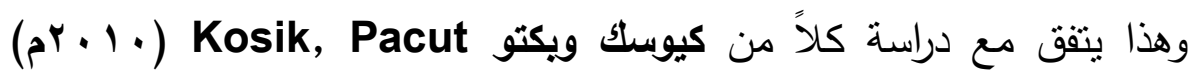
(9 (1) حيث قامت هذه الدراسات بتوضيح أن التسويق الرياضي يحتاج إلى دراسة واعية 
مبنية على أسس وقواعد علمية سليمة، وهو أحد العوامل المهمة التي تستتد عليها كل مؤسسة ناجحة وخاصة منها الأندية الرياضية الكبيرة، التي تعتمد على واقع الحاجة والموضوعية ومتطلبات النهوض بالثباب بصورة عامة.

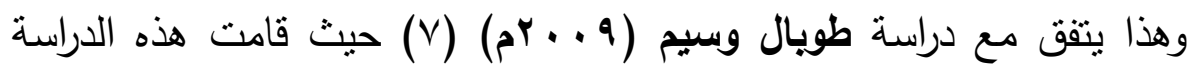
بتوضيح إن التسويق الرياضي كغيره من أنواع التسويق الأخرى وهو لا يقل أهمية عنها ، وتتمثل مصادر التمويل في الرياضة بما يأتي: • الترخيص باستخدام العلامات والشعارات على المنتجات ووسائل الخدمات. • الإعلان على ملابس وأدوات اللاعبين. • الإعلان على المنشآت الرباضية. • استثمار المرافق والخدمات في الهيئات الرياضية. • عائدات تذاكر الدخول للمباريات والمناسبات الرياضية.

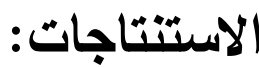

انطلاقًا من نتائج البحث وفي ضوء المنهج المستخدم وفي حدود العينة وأداة جمع البيانات، توصلت الباحثة إلى الاستتناجات الآتية: •لا يتم استخلال الملاعب والمنشآت الرياضية بمحافظة أسوان على الشكل الأمنل ، كما لا يوجد استثمار للعائد المادي من تأجير المنشآت الرياضية بالمحافظة . •الأدوات بالمنشآت الرياضية غير مطابقة للمواصفات القانونية ، ولا نوجد أماكن معدة لحفظها من التلف ، كما لا توجد وحدة صيانة متخصصة بالملاعب . •لا توجد لائحسة ماليـة لتـأجير المنشـآت الرياضـية بمحافظــة أسـوان، كمـا لا يوجد متخصصون لوضع اللوائح والتشريعات الخاصة بتسويق منشآتها الرياضية ـ •لا تتتاسب الميزانيات الحالية مع أهداف ومتطلبات المنشآت الرياضية بمحافظة أسوان 


\section{التوصيات:}

في حدود عينة البحث وفى ضوء النتائج التي توصلت اليها الباحثة نوصى الباحثة بالاتي:

العمل على وضع قوانين ونظم ولوائح تتريعية جديدة تساعد على جذب المستثمرين وتسويق المنشآت الرياضية بمحافظة أسوان.

يجب عقد دورات تدريبية لمسؤولي المنشآت الرياضية في مجال التسويق الرياضي والتمويل الرياضي مع تعديل موقفهم المالي.

عمل دراسة جدوى لاحنياجات المنشآت الرياضية بمحافظة أسوان وفقاً لخطة علمية واضحة ومدروسة مما يسهل تسويق هذه المنشآت الرياضية.

\section{المراجع العربية والأجنبية:}

ا ـالهيئة العامة للشباب والرياضة (9 9 . . بم): إدارة الهيئات والمنشآت الرياضية، دار الإعلام والنشر ، الكويت. - م.

r . حسام رضوان كامل ( . . . r م) اقتصـاديات الاتحادات الرياضية الأوليمبية المصرية دراسة تحليلية ، رسالة دكتوراه ، كلية التربية الرياضية للبنين بالقاهرة ، جامعة حلوان. r.خالا عبد العاطى ( . . . rم): اساليب مقترحه للتسويق البطولات الرياضيه فى ج.م.ع، رسالة ماجستير ، كلية التربية الرياضية للبنين، جامعة حلوان ع .سمير عبد الحميل علي (Y . . rم): رؤية علمية لإدارة الهيئات الرياضية، الرياض، جامعة الملك سعود. 
ه. سيد محمود الهوارى(r . . r م): " الإدارة، الأصول والأسس العلمية للقرن اب " ، مكتبة عين شمس، القاهرة.

צ.طلعت أسعد عبد الحميد ( . . . F م):"التسويق الفعال ، كيف تواجة تحديات القرن الحادي والعشرين ، دار النهضة العربية ، القاهرة.

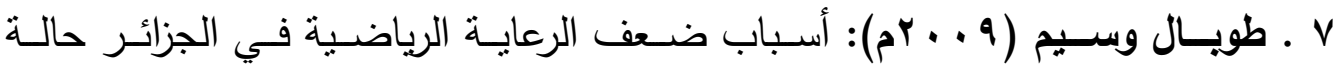
الاتحاديات الرياضية الجزائريـة، رسالة ماجستير ، معهد التربية البدنية والرياضية، جامعة الجزائر.

^.عصام فرج مسعود (9 . . rم):"على تقويم الموارد المادية والبشرية بمراكز الثباب •بمحافظة المنوفية ، رسالة ماجستير

9. على محمد السلمى( 1 . . rم): إدارة الموارد البشرية الاستراتيجية مكتبة دار غريب، القاهرة.

• 1 ـ محمد رجب أحمد جبريل( 1 . r م):" ترويج البطولات والمباريات الرياضية بإستخدام المفهوم الحديث للتسويق ، رسالة ماجستير ، كلية التربية الرياضية للبنين ، جامعة حلوان

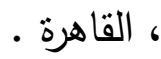

11 ـ محمود أحمد الخطيب( 1 . . rم): " الإدارة الحديثة"، مطبعة الإسراء، القاهرة. r ا .معتز مصطقى عبد الجواد شيحة (1 . . Y) مدخل إدارى معاصر لإستثمار المؤسسات الرياضية

ب ا .مني راشثد الغيص ( . . . rم): مبادئ التسويق، منشورات ذات السلاسل، الكويت. 
ع ا.نصر عبد الحليم نصر الجمل (V . . P م):"دراسة تحليلية لتسويق المنشأت الرياضية بالقوات المسلحة" ، رسالة دكتوراة ، كلية التربية الرياضية ، جامعة طنطا ـ

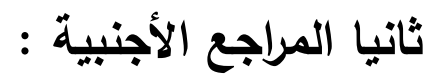

15-Defrance Jacque (2005): Sociologie de sport, edition de la decouverte Paris

16-George Karils(2003): City and sport Marketing Strategy (The Case of Athens), the journal Number 2, Spring 2-3.

17-George Karils(2003): City and sport Marketing Strategy (The Case of Athens), the journal Number 2, Spring 2-3.

18-Jeoung , Haklee,(2000) Sport marketing Strategies throw the analysis of sport consumer Behaviour and Factors University of Minnesota.

19-Kosík, M. (2010): Funding of Sports Activities for Children and Youth in the Czech and Slovak Republics. In: Sport Science Review, Romania.

20-Stewart and other(2003): Sport consumer typologies $A$ critical review, Sport Marketing Journal, Quarterl 12(4) DEC. 


\section{ملخص عربى}

الملخص باللغة العربية: واقع تسويق المنشآت الرياضية بمحافظة أسوان "

\section{المقدمة ومشكلة البحث:}

تعد الإدارة عملية إنسانية مستمرة تعمل على تحقيق أهداف جيدة وعلى استخدام الجهد البشرى في الاستعانة بالإمكانيات البشرية والمادية المتاحة، وذلك الكيك في شكل نشاط إنساني متكرر ومستمر، وهذا النشاط يوجد في كل المؤسسات وعلى كافة المستويات سواء كانت هذه المؤسسات حكومية أو أهلية (1) (1: () . ولكى تسنطيع الهيئة الإدارية مواجهة احتياجات المجتمع وتحقق أهدافها بنجاح يتطلب على القائمين بها وقادتها أن يكون لديهم رؤية واحدة مشتركة في

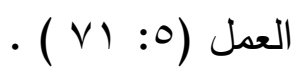

ولقد بدأت الإدارات في المؤسسات المعاصرة تلجأ إلى تطوير الأفكار والمفاهيم وإتباع أساليب إدارية تتسم بالجرأة والتحرر ونتطلق جميعها من منطلق الرغبة فى تعظيم فرص النجاح لتحقيق رغبات السوق (9: بr ) ) .

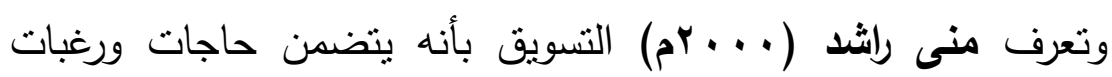
المستهكين أو المستقيدين وتفهمها في ضوء طاقات المؤسسة ثم تعريف المختص بتلك الرغبات والحاجات حتى بمكن تشكيل المنتج والخدمة وفقا لها ثم

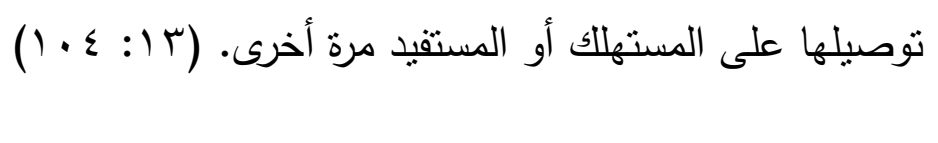




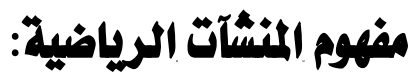

وعرفها سمير عبد الحميد (Y . . . بأنها مؤسسات تربوية تهدف إلى إعداد

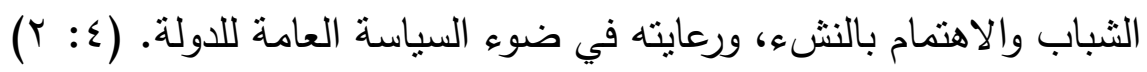
مشكلة البحث وأهميته: - مابه ومن خلال اطلاع الباحثة علي بعض المراجع والدوريات واللوائح المنظمة لعمل المنشآت الرياضية وما اشارت به بعض الدراسات بأهمية النسويق في

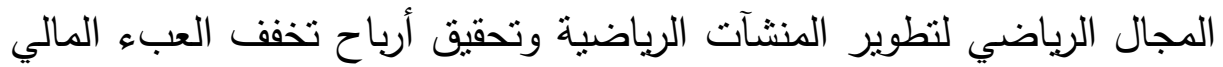
عن الدولة وتواكب سعيها وتأكيدها علي أهمية تطوير الرياضة المصرية ، وعمل تغيير جذري في صناعة الرياضة وتحويلها من نشاط مستهلك الي نشاط اقتصادي عن طريق الاخذ بالأساليب العلمية الحديثة في الإدارة والتسويق

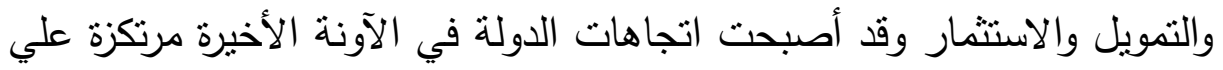
توسيع قاعدة التسويق الرياضي من خلال المنشآت الرياضية وزيادة العائد المادي والاقتصادي لها عن طريق انشاء وتطوير وتسويق المنشآت الرياضية بمحافظات جمهورية مصر العربية وهي (الأندية ـالصالات -حمامات السباحة -الملاعب المفتوحة - فنادق الرياضيين - صالات اللياقة البدنية - وحدات الطب الرياضي ) وغيرها من المنشآت الرياضية .

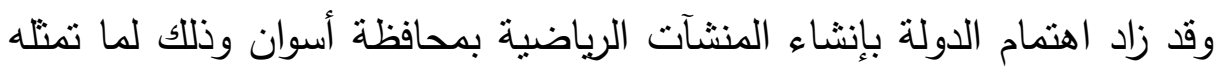
من مناطق سياحية تكون مصدر جذب وانتباه للكثير من الجنسيات المختلفة في العالم ،حيث ان لديها من الحضارة والتاريخ ما يؤهلها لذلك ، حيث بها الكثير من اثار العالم وتتوفر لايها عوامل الجذب السياحي مما يشجع علي جذب رؤوس الأموال والاستثمار في المناطق السياحية والرياضية بمحافظة أسوان ـ ومن خلال الدراسة الاستطلاعية التي أجرتها الباحثة علي بعض مديري المنشآت الرياضية بمحافظة أسوان تبين انه يوجد قصور في اللوائح والقوانين

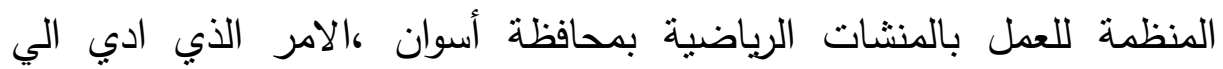


مواجهة المنشآت الرياضية لكثير من المعوقات التي تحول دون تسويقها بالطريقة

$$
\text { أهمية البحث : }
$$

ترجع الأهمية العلمية لهذا البحث في الاعتبارات التالية:

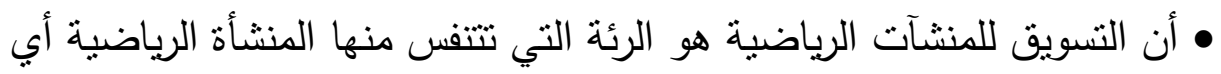
ما كان مصادر دخلها فأن التسويق هو عماد التمويل. • تقوم الإدارة العليا بعملية التخطيط للتسويق واتخاذ القرارات بناءاً عن ما تقدمه هونه

$$
\begin{aligned}
& \text { الإدارة المباشرة من معلومات إليها. } \\
& \text { هدف البحث: } \\
& \text { يهدف البحث إلى: }
\end{aligned}
$$

• التعرف على الواقع الحالي لتسويق المنشآت الرياضية بمحافظة أسوان.

$$
\text { تساويلات البحث: }
$$

•ما هو الواقع الحالي لتسويق المنشآت الرياضية بمحافظة أسوان؟

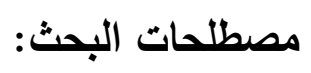

$$
\text { التسويق الرياضي: }
$$

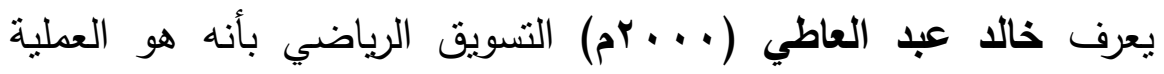
القائمة المتبادلة المنافع بين المنتج (البطولات الرياضية) وبين المستهلك (المشاهدين) لتحقيق هدفه الأساسي لإشباع وتوفير احتباجات المجنمع المعنوي

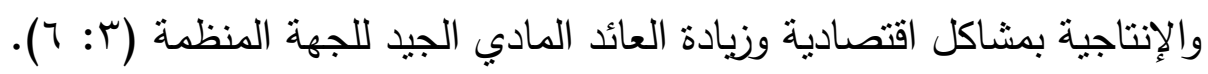

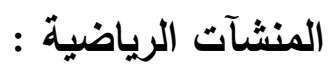
عرفت الهيئة العامة للشباب والرياضية (9 . . ب م) المنشآت الرياضية بأنها: المرافق الرياضية والأندية ومراكز الثباب والصالات المفتوحة والمغطاة التي تم إنشائها لتمكين أفراد المجتمع في مراحل سنية مختلفة من ممارسة هواياتهم ونشاطاتهم الرياضية. (1: ( ) 


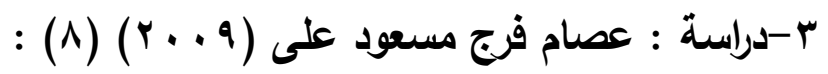

موضوع الاراسة :"تقويم الموارد المادية والبشرية بمراكز الثباب بمحافظة المنوفية" موصوعة

\section{أهداف الاراسة : (1)}

1 - التعرف على الموارد المادية والبشرية بمراكز الثباب بمحافظة المنوفية . r- إقتراح الحلول المناسبة للمشكلات المرتبطة بالموارد المادية والبشرية .

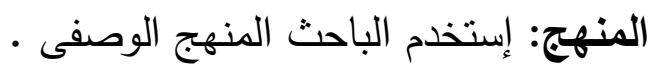
العينة : بلغ إجمالى أفراد العينة (·VV) فرداً بمراكز الثباب بمحافظة المنوفية

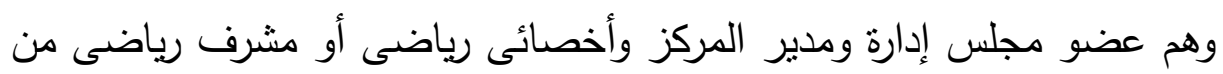
مراكز شباب المدن والقرى بمحافظة المنوفية أدوات جمع البيانات : ثم جمع البيانات عن طريق الإستبيان .

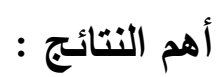

تم التوصل إلى أهم المشكلات المرتبطة بالموارد المادية والبشرية بمراكز الثباب بمحافظة المنوفية ، وأمكن وضع الحلول المناسبة لتلك المشكلات للنهوض بمراكز شباب القرى والمدن بمحافظة المنوفية .

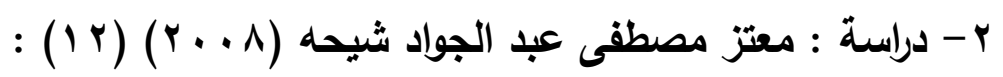
موضوع الدراسة : "مدخل إدارى معاصر لإستثمار المؤسسات الرياضية". أهداف الدراسة : التعرف على عوامل دراسات الجدوى كمدخل إدارى معاصر

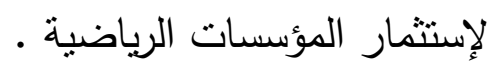

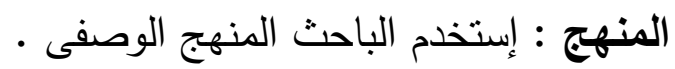

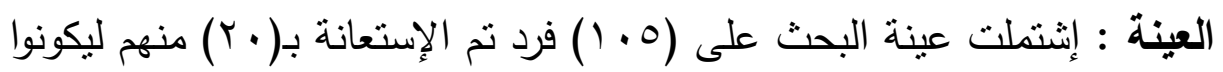
عينة الدراسة الإستطلاعية وبلغ حجم العينة (10) فرد من مسئولى الإدارة العليا

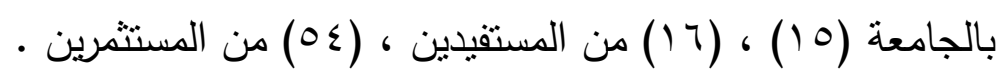
أدوات جمع البيانات : إستخدم الباحث المقابلة الثخصية ، الإستبيان . 


\section{أهم النتائج :}

من مجالات الإستثمار التى يمكن أن تحقق عائداً مالياً لإستاد الجامعة

حقوق البث التلفزيونى ، نادى صحى ، صالة مغلقة للألعاب الرياضية . وجود إقبال من المستقيدين على الخدمات أو الأنشطة التى سيقدها إستاد الجامعة كمشروع إستثمارى · مترك

التمويل الحكومى مصدر غير كافى لتمويل إستاد الجامعة كمؤسسة رياضية .

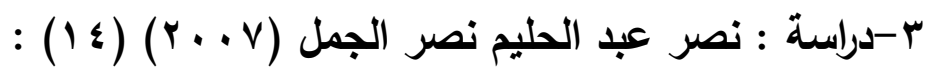

موضوع الدراسة : "دراسة تحليلية لتسويق المنشأت الرياضية بالقوات المسلحة ".

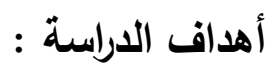
- دراسة وتحليل الأساليب التسويقية المقترحة والنماذج المعمول بها ـ - دراسة تحليلية لتسويق المنشآت الرياضية بالقوات المسلحة . -المنهج : إستخدم الباحث المنهج الوصفى ( الدراسات المسحية ) .

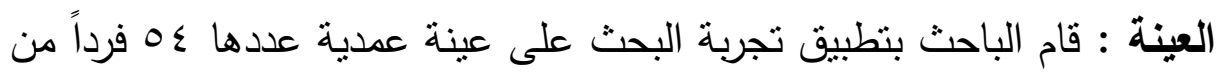

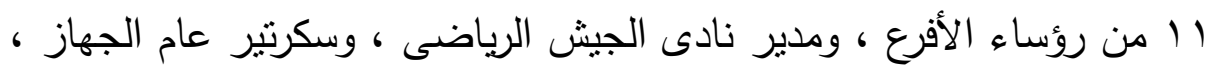
والمشرف العام على مجمع السباحة بالقوات المسلحة ، ومدير للمراكز الرياضية وسا قائداً للسرايا

أدوات جمع البيانات : المقابلة الشخصية وإستمارة الإسنبيان .

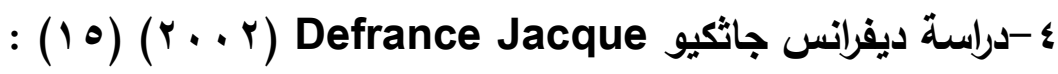
موضوع الدراسة : التسويق الرياضى عبر الإنترنت دراسة إستطلاعية عن مواقع

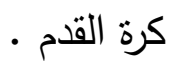
أهداف الدراسة : التعرف على رسالة مواقع كرة القدم فى إستراليا ونيوزلندا وإنجلترا وحساب الهوامش والتخطيط للتسويق • المنهج : المنهج الوصفى ( الدراسات المسحية ) . 


$$
\begin{aligned}
& \text { العينة : مسئولى مواقع الإنترنت والخبراء . }
\end{aligned}
$$

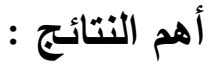

- إستخدام الإنترنت بعتبر وسيلة لتسويق الرياضة وآداة إدارية فعالة . - مكونات الإستراتيجية التسويقية هى تحديد الأهداف بدقة ، تتمية المبيعات ، وجود تكنولوجيا جديدة فى الإتصالات وفى العلاقات العامة .

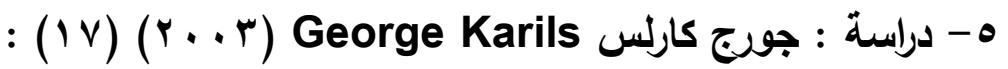

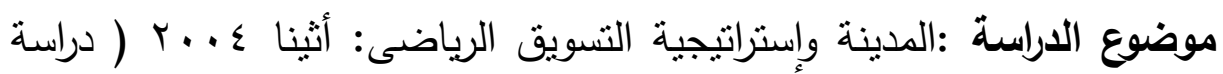
حالة ). أهداف الاراسة : التعرف على ثأثثر إستضافة الألعاب الأوليمبية على السياحة ومناقثنة بعض إستراتيجيات التسويق التى يجب على أثنيا إتباعها لكى تعظم الآثار الإيجابية للسياحة .

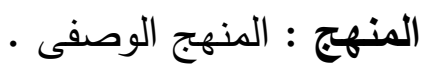
أهم النتائج : - إستضافة الألعاب اليونانية فى عام ع ... ينتج عنه آثار اقتصادية هامة •لبونان

- زيادة معدل النمو فى الناتج المحلى وإتاحة وظائف جديدة وترويج المنطقة . - مصدر زيادة الأنشطة الإقتصادية هو المال القادم من السائحين الأجانب . צ- دراسة : إستيورت وأخرون Stewart موضوع الدراسة : المستهلك الرياضى : أنواع متعددة ( وجهة نظر نقدية ) . أهداف الدراسة : التعرف على أنواع وسلوكيات ودوافع المستهلك الرياضى .

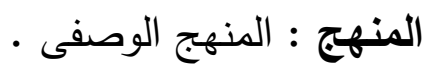
العينة : تتكون من المستهلكين رياضياً ومسئولى التسويق الرياضى . لوصى

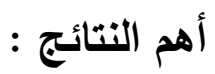


- إهتمام المسوقين الرياضيين تركيز قليلاًُعلى الإتجاهات الفلسفية الإجتماعية فقط .

- ويعطون تركيز على الجوانب الثقافية الإقتصادية .

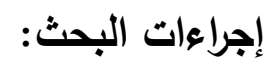
منهج البحث:

استخدمت الباحثة المنهج الوصفي ( أسلوب الدراسات المسحية ) بخطواته وإجراءاته وذلك لمناسبته لتحقيق أهداف البحث مجتمع البحث:

يشمل مجتمع البحث مجالس إدارات (الأندية - الصالات الرياضية -

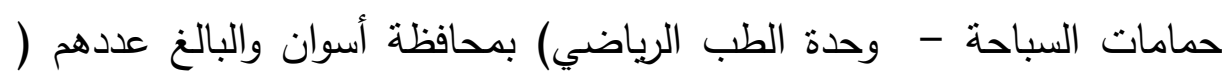

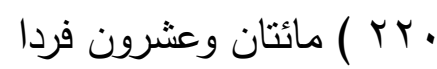

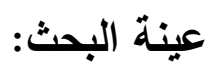

تم اختيار عينة البحث الطبقية العشوائية منبعض اعضاء مجلس إدارات الأندية والصالات وحمامات السباحة ووحدة الطب الرياضي علي عدد (00) فرد.

\section{أدوات جمع البيانات:}

تحليل الوثائق والسجلات :

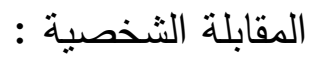

استمارة استبيان : ( إعداد الباحثة ) 


\section{" The reality of marketing sports facilities in}

\section{ASWAN" Introduction and Research Problem:}

The Department is a continuous humanitarian operation that works to achieve good goals and to use the human effort to utilize the available human and material resources in the form of repeated and continuous human activity. This activity exists in all institutions and at all levels, whether governmental or civil (11:1)

In order for the administrative body to meet the needs of the society and achieve its objectives successfully requires its managers and leaders to have a common vision in the work (5: 71).

Administrations in contemporary institutions have begun to develop ideas and concepts and to adopt bold and liberal management styles, all of which are based on the desire to maximize the chances of success in order to achieve market desires (9:32).

Mona Rashed (2000) defines marketing as containing the needs and desires of consumers or beneficiaries and understanding them in the light of the capacities of the organization and then defining the specialist of these desires and needs so that the product and service can be formed according to it and then delivered to the consumer or beneficiary again. 
(13: 104)

The concept of sports facilities:

Samir Abdel Hamid (2002) defined it as educational institutions aimed at preparing young people and caring for the youth, and taking care of them in the light of the general policy of the state. (4: 2$)$

\section{Search problem and its importance:}

And through the researcher acquainted with some of the references, periodicals and regulations governing the work of sports establishments, as indicated by some studies the importance of marketing in the field of sports to develop sports facilities and achieve profits that reduce the financial burden of the state and keep pace with its quest and emphasis on the importance of the development of Egyptian sports, Consumer activity to economic activity by taking the modern scientific methods in management, marketing, finance and investment has become the state's trends in recent times based on the expansion of the base of sports marketing through sports facilities and increase the return Physical and economic development through the establishment, development and marketing of sports facilities in the governorates of the Arab Republic of Egypt (clubs, lounges - swimming pools - open fields - athletes hotels - fitness rooms - sports medicine units) and other sports facilities. 
The interest of the state in the establishment of sports facilities in ASWAN, as it represents the tourist areas attract attention to many of the different nationalities in the world, since they have the civilization and history to qualify for it, as it owns more than one third of the world's effects and has the attractions of tourism Encourages the attraction of capital and investment in tourist and sports areas in ASWAN.

The study conducted by the researcher on some of the managers of sports facilities in ASWAN, it was found that there is a deficiency in the regulations and laws governing the work of sports facilities in ASWAN, which led to the confrontation of sports facilities for many of the obstacles that prevent the marketing in the best way.

research importance :

The scientific importance of this research is due to the following considerations:

- Marketing for sports facilities is the lung from which the sports establishment breathes, whatever its sources of income, marketing is the mainstay of funding.

- The senior management of the process of planning for marketing and decision-making based on the direct information provided by the management.

\section{Search Goal:}

The research aims to: 
- Identify the current reality of marketing sports facilities in ASWAN.

\section{Search questions:}

- What is the current reality of marketing sports facilities in ASWAN?

\section{Search terms:}

\section{Sports Marketing:}

Khalid Abdul Ati (2000) defines sports marketing as the process of mutual benefit between the product (sports championships) and the consumer (viewers) to achieve its primary goal to satisfy and provide the needs of the morale and productivity with economic problems and increase the good financial return of the regulator $(3: 6)$.

\section{Sports facilities :}

The General Authority for Youth and Sports (2009)

defined sports facilities as: sports facilities, clubs, youth centers, open and covered halls that were established to enable members of the community in various stages of the year to practice their hobbies and sports activities. (1:2)

\section{1 - Study: Issam Faraj Masoud Ali (2009) (8):}

Subject of the study: "Evaluation of physical and human resources in youth centers in Menoufia Governorate"

\section{Objectives of the study :}

1- Identifying the physical and human resources in youth centers 
in Menoufia governorate.

2. Proposing appropriate solutions to problems related to material and human resources.

Methodology: The researcher used the descriptive approach.

Sample: The total sample of the sample (270) individuals in the youth centers in the governorate of Menoufia, a member of the board of directors and director of the center and a sports specialist or sports supervisor of the youth centers of cities and villages in the governorate of Monofiya.

Data collection tools: Data collected by questionnaire. Main results:

The most important problems related to physical and human resources were reached at the youth centers in Menoufia governorate. It was possible to develop appropriate solutions to these problems to promote youth centers of villages and cities in Menoufia governorate.

\section{2 - Study: Moataz Mustafa Abdul Jawaad Shihah (2008)}

\section{(12):}

Subject of the study: "A modern administrative approach to the investment of sports institutions".

Objectives of the study: Identify the factors of feasibility studies as a modern administrative entry for the investment of sports institutions.

Methodology: The researcher used the descriptive approach. 
The sample consisted of (105) individuals, 20 of them were used to be the sample of the exploratory study, and the sample size was (85) members of the senior management of the university (15), (16) of the beneficiaries, (54) of the investors.

Data collection tools: Use the interviewer interview questionnaire.

\section{Main results:}

One of the areas of investment that can make a financial return to the University Stadium is television rights, a health club, a closed gymnasium.

- There is a demand from the beneficiaries for the services or activities that will be provided by the University Stadium as an investment project.

- Government funding is insufficient to finance the university's stadium as a sports institution.

2 - Study: Nasr Abdel Halim Nasr Al-Jamal (2007) (14):

Subject of the study: "Analytical study for the marketing of sports facilities in the armed forces."

\section{Objectives of the study :}

- Study and analysis of proposed marketing methods and models.

- Analytical study for the marketing of sports facilities in the armed forces.

- Methodology: The researcher used the descriptive approach 
(survey studies).

Sample: The researcher applied the research experiment to a sample of 54 members of the 11 branch heads, the director of the Army Sports Club, the Secretary General of the Agency, the General Supervisor of the swimming pool in the Armed Forces, the director of the sports centers and 13 leaders of the Saraya Data collection tools: personal interview and questionnaire form.

\section{4 - Study Defrance Jacque (2002) (15):}

Subject of the study: sports marketing online A survey of football sites.

The objectives of the study: to identify the message of football sites in Australia, New Zealand and England and the calculation of margins and marketing planning.

Approach: descriptive approach (survey studies).

Sample: Web site experts and experts.

Main results:

- Internet use is a way to market sports and an effective management tool.

- The components of the marketing strategy are the precise objectives, sales development, the presence of new technology in communications and public relations.

5 - Study: George Karils (2003) (17):

Subject of Study: City and Strategy of Sports Marketing: Athens 2004 (case study). 
Objectives of the study: To understand the impact of hosting the Olympic Games on tourism and discuss some marketing strategies that Athens should follow in order to maximize the positive effects of tourism.

Curriculum: descriptive approach.

The study divided the Olympic Games market into:

Olympic Market.

2- The internal tourist market.

3- The international tourist market.

\section{Main results:}

- The hosting of the Greek Games in 2004 will have significant economic implications for Greece.

- Increase the rate of growth in the GDP and make new jobs and promote the region.

- The source of the increase in economic activities is the money coming from foreign tourists.

6 - Study: Stewart and others Stewart (2003) (20):

Subject of study: Sports consumer: multiple types (critical point of view).

Objectives: To identify the types, behaviors and motivations of the sports consumer.

Curriculum: descriptive approach.

Sample: Consists of sports consumers and sports marketing officials. 


\section{Main results:}

- The interest of sports marketers focus only a few of the social philosophical trends.

- They focus on cultural and economic aspects.

\section{Search procedures:}

\section{Research Methodology:}

The researcher used the descriptive method (the method of survey studies) in his steps and procedures in order to achieve the objectives of the research

\section{research community:}

The research community includes the boards of directors (clubs, gymnasiums, swimming pools, sports medicine unit) in ASWAN Governorate, which are (220) twenty two hundred individuals

\section{The research sample:}

The random stratified sample was selected from some members of the board of directors of clubs, gymnasiums, swimming pools and the sports medicine unit on the number of (55) individuals. 